Wameedh Khider Abbas Abbas, Matthias Linnemann, Elmar Baumhögger, Jadran Vrabec

\title{
Experimental study of two cascaded organic Rankine cycles with varying working fluids
}

Journal article | Accepted manuscript (Postprint)

This version is available at https://doi.org/10.14279/depositonce-11722

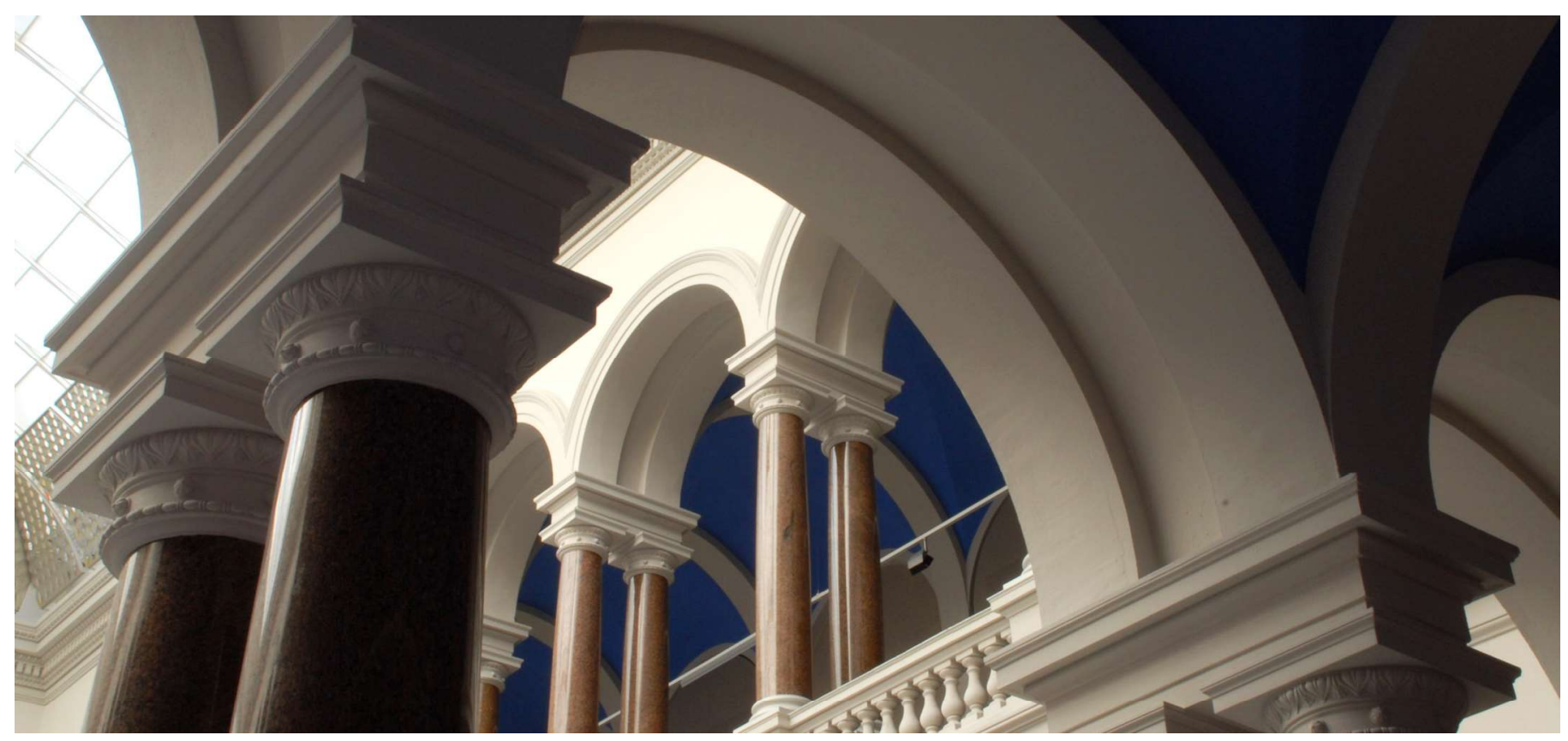

Abbas, W. K. A., Linnemann, M., Baumhögger, E., \& Vrabec, J. (2021). Experimental study of two cascaded organic Rankine cycles with varying working fluids. Energy Conversion and Management, 230, 113818. https://doi.org/10.1016/j.enconman.2020.113818 


\title{
Experimental study of two cascaded organic Rankine cycles with varying working fluids
}

Wameedh Khider Abbas Abbas ${ }^{\mathrm{A}}$, Matthias Linnemann ${ }^{\mathrm{B}}$, Elmar Baumhögger ${ }^{\mathrm{A}}$, Jadran Vrabec $^{\mathrm{B}}$

\author{
A Thermoynamics and Energy Technology, University of Paderborn, Warburger Straße 100, \\ 33098 Paderborn, Germany \\ B Thermodynamics and Process Engineering, Technical University of Berlin, Ernst-Reuter- \\ Platz 1, 10587 Berlin, Germany
}

\begin{abstract}
Organic Rankine cycles convert low-temperature heat from different sources, like solar, geothermal or biomass, into electricity and may thus help to meet the energy demand in an environmentally friendly way. While single ORC systems have been studied extensively, there are only very few experimental works on systems consisting of two cascaded organic Rankine cycles (two-ORC). In this work, an experimental study is carried out on the performance of a system of two-ORC system that consists of a high temperature (HT) cycle and a low temperature (LT) cycle. Each cycle is composed of the four significant components, i.e. expander, evaporator, condenser and pump, while the LT cycle is equipped with a throttle as expansion device. The HT cycle utilized heat from electrical heaters, while the LT cycle was driven by the waste heat from the HT cycle. The test rig utilizes Therminol 66 as a source that is heated up by electrical heaters with a power of $158 \mathrm{~kW}$. Propane, butane, pentane and cyclopentane are chosen as working fluids for the present experiments. Parameter variations are carried out to study the thermodynamic characteristics of each cycle. The aim is to investigate the HT cycle performance considering turbine power output, thermal efficiency and exergy efficiency. The effect of the HT cycle on the LT cycle is examined by studying the heat transfer rate between the two cycles, characteristics of heat exchangers and pinch point temperature difference. $\mathrm{A}$ further goal is to explore the system performance under different conditions to maximize the exergetic utilization of the heat source. The results confirm that turbine power output and thermal efficiency increase with heat source temperature and turbine inlet pressure in the HT cycle. The maximum achieved thermal and exergy efficiencies are 5.5\% and 20.2\%, respectively, while the maximum turbine power output is $4.92 \mathrm{~kW}$. Heat transfer measurements show that the maximum transferred heat flow from the HT cycle to the LT cycle is $23 \mathrm{~kW}$ when pentane is used as a working fluid. Temperature profiles and the pinch point temperature difference in the heat exchangers of both cycles are assessed under conditions where the highest
\end{abstract}


turbine power is obtained. The experimental tests are promising and show that the two-ORC system is suitable to utilize heat sources in various temperature ranges.

Keywords: organic Rankine cycle, two-ORC system, heat source temperature, working fluids, pinch point temperature difference.

Corresponding author: Jadran Vrabec, tel.: +493031422755, fax: +4930314 22406, E-mail: vrabec@tu-berlin.de

\section{Introduction}

Global warming and its impact on climate change has received much attention in recent years. Consequently, many alternative technologies and solutions have been introduced to reduce the dependence on fossil fuels. The organic Rankine cycle (ORC) is a suitable technology for power generation because it can be driven by heat from different sources. ORC may generate power from low-temperature and waste heat that might otherwise be emitted into the environment $[1,2]$. The heat source has an essential role in the design process of such plants. Therefore, ORC systems have been devised for various low- and medium-temperature sources [3]. The ORC has the same operating scheme as the Rankine cycle, but utilizes organic fluids instead of water. The working fluid selection is a key step for the design and optimization of ORC under given heat source characteristics. A large number of studies highlighted the importance of selecting appropriate working fluids [4].

Saleh et al. [5] tested 31 working fluids for different ORC layouts in the context of geothermal plants with temperatures varying from $30^{\circ} \mathrm{C}$ to $100{ }^{\circ} \mathrm{C}$. The authors demonstrated that supercritical fluids recovered the largest amount of heat, while the situation was reversed for high-boiling subcritical fluids. Bao et al. [6] reviewed different working fluids and turbines for ORC plants. Their analysis included a study of thermo-physical properties of working fluids and their influence on ORC performance, along with a comparison of working fluids that are pure components or mixtures. It was pointed out that mixtures with an appropriate composition may improve overall system efficiency. Ma et al. [7] published a study on system performance of medium- and low-temperature ORC systems. Their study included a systematic screening of 70 working fluids with different thermo-physical properties and reported a major dependence of specific turbine volume and thermal efficiency on their critical point temperature. 
Many researchers focused on the selection of suitable heat sources for different ORC systems to modify the objective functions, like output power, thermal efficiency, exergy efficiency or heat transfer. The selection included solar energy [12], geothermal energy [13], biomass [14] or liquefied natural gas (LNG) [15].

A considerable number of investigations focused on developing different ORC architectures. In this context, ORC systems with multi-cycle layouts have received attention in recent years [9]. One of these architectures is the two-ORC system, where each cycle has a different working fluid, different temperature and pressure levels as well as different mass flow rates. Generally, a two-ORC system consists of a HT cycle (topping ORC) and a LT cycle (bottoming ORC). The HT cycle is driven by the main heat source, while the LT cycle utilizes the residual heat from HT cycle or a secondary heat source [10]. Several theoretical investigations have been presented to identify the advantages of multi-ORC systems. Wang et al. [8] studied a two-ORC system driven by waste heat of a diesel engine using R245fa and R134a as working fluids. The authors assessed the influence of turbine efficiency, evaporation pressure of the HT cycle and condensation temperature of the LT cycle on the system performance. They reported that the use of a two-ORC system can improve the net power by up to $22 \%$. Braimakis et al. [10] considered seven working fluids to explore the exergetic optimization of a two-ORC system, where the heat source temperature ranged from $100{ }^{\circ} \mathrm{C}$ to $300{ }^{\circ} \mathrm{C}$. The authors developed a routine to calculate the optimal evaporation pressure as well as the pinch point temperature difference during evaporation and condensation to increase power output. Thereby, the exergetic efficiency increased up to $25 \%$ by employing cyclopentane and butane for the HT and the LT cycle, respectively. They found that the twoORC layout is suitable when the critical temperature difference between the working fluids in the HT- and LT-temperature cycles is low. Sung and Kim [16] analyzed a two-ORC system to recover waste heat from engine exhaust. They revealed that the proposed two-ORC system may enhance the performance of the engines such that the net power output may be $5 \%$ higher than that of regular ORC systems. The authors reported that pentane and R125 are the best option for the HT cycle and the LT cycle, respectively. Mehrpooya et al. [17] optimized a two-ORC layout by studying the influence of 11 thermodynamic parameters on the system performance. The authors also reported a relation between the improvement of the exergy efficiency and the investment cost of the ORC layout. Yang et al. [18] proposed a two-ORC layout for heat recovery from a compressed natural gas engine. The authors investigated the effect of evaporation pressure and condensation temperature of the HT cycle on the system performance, while the same parameters were kept constant in the LT cycle. Their results indicated that the 
maximum power output and the thermal efficiency are $23.62 \mathrm{~kW}$ and $10.19 \%$, respectively. Kosmadakis et al. [19] studied 33 refrigerants to select the optimal working fluid for the use in the HT cycle of a two-ORC layout. They discussed the environmental effects and performance of working fluids under high-temperature conditions. They found that R245fa has the best properties among the selected working fluids according to its high turbine power, good thermal efficiency and low impact on the environment. The thermodynamic analysis of a two-ORC system was discussed in the work of Xue et al. [20]. The authors presented numerical thermodynamic models to investigate the effect of different parameters on the system performance. They showed that the maximum achieved net power output was $1.78 \mathrm{MW}$, with maximum thermal and exergy efficiency of $25.64 \%$ and $31.02 \%$, respectively. Preissinger et al. [21] made an exergy analysis of a biomass-fired two-ORC system, investigating 35 different working fluids. The study concluded that the achieved thermal and exergy efficiencies were $36 \%$ and $60 \%$, respectively. The authors showed that the exergy efficiency is affected by the LT cycle working fluid more than by the HT cycle working fluid. Ayachi et al. [22] assessed the exergy efficiency of regular and two-ORC systems, reporting that the two-ORC system may provide an exergy efficiency of about $42 \%$, which is higher than that of regular ORC systems. Their study also points out a strong relation between critical temperature of the working fluid and exergy efficiency. In addition, the highest efficiencies may be achieved by subcritical cycles. Yun et al. [23] proposed a parallel two-ORC system for marine applications, comparing it with regular ORC systems for waste heat recovery. They studied the advantages of two-ORC layouts and considered four models based on actual sailing data of a container ship. They demonstrated that the two-ORC system may generate more power output than regular ORC. Their paper reported that the proposed two-ORC system can be considered for different marine applications due to its ability to recover waste heat under different operational conditions. Choi et al. [24] studied multi-ORC (two- and three-ORC) systems for LNG cold energy recovery for power production. The authors presented that cycle efficiency, thermal efficiency and turbine power output increase with the number of system cycles. The highest turbine power output was gained with a three-ORC system by using propane as a working fluid. Li et al. [25] proposed a cascaded two-ORC power generation plant using LNG and solar energy as heat source and they also investigated the influence of working fluids on system performance. The authors discussed the design of turbines for ORC and found that the volume ratio of their expanders is much smaller than that of regular ORC. Shu et al. [26] analyzed a two-ORC layout with respect to system performance to recover waste heat from high-temperature exhaust and engine coolant. They utilized water and six refrigerants for the HT cycle and the LT cycle, respectively. Their 
results revealed that the maximum achieved power output and exergy efficiency are $36.77 \mathrm{~kW}$ and 55\%, respectively. The selection of the working fluids for the two-ORC system was discussed in the paper of Emadi et al. [14]. They studied the applicability of two-ORC technology for waste heat recovery from a solid-oxide fuel cell system integrated with a gas turbine. The authors investigated 20 combinations of working fluids and proposed the combination of pentane and ethane for the HT and the LT cycle, respectively. According to their study, the two-ORC system produced electrical power of $1040 \mathrm{~kW}$ with an exergetic efficiency of $51 \%$.

This literature review of theoretical studies indicates that articles dealing with twoORC archticture are devoted to the effectiveness of this system and may contribute to the environmentally friendly power supply [28]. Despite many publications on two-ORC technology, there is still a lack of experimental studies and practice in turning theoretical research into tangible results.

Experimentally, Linnemann et al. [27] assessed a cascaded two-ORC system. Their study presented a thermodynamic analysis of different parameters by utilizing waste heat from a biogas combined heat and power plant. They found that the maximum achievable thermal efficiency of the HT cycle was $15.20 \%$ by using toluene as working fluid, while it was $8.90 \%$ for the LT cycle by using SES36 as a working fluid. Ntavou et al. [43] practically tested and compared the system performance for both regular and two-ORC systems over a wide range of heat flow input. Their results showed a thermal efficiency of $7 \%$ and turbine power of $6.30 \mathrm{~kW}$ for a regular ORC, while the values of the two-ORC improved to $9.9 \%$ and $7.7 \mathrm{~kW}$, respectively. Yu et al. [11] investigated a cascaded steam-ORC experimentally, which consisted of a HT cycle and a LT cycle to recover waste heat from a diesel engine. They pointed out that the maximum power output was $12.7 \mathrm{~kW}$.

The rather large literature review of the present work indicates that the two-ORC system may be highly promising and effective for waste heat recovery applications, as elaborated in numerous theoretical studies. However, the very few experimental studies found that two-ORC system are considered to be immature and there is a significant increase of complexity with respect to the operating conditions of two-ORC systems. To improve this technology, further practical investigations are thus necessary, which was the aim of this work. It was attempted to fill some of the gaps with experimental investigations for two-ORC system technology by applying a wide range of operating conditions and parameters. 
This paper presents an experimental investigation of a cascaded two-ORC system by considering four hydrocarbon working fluids. The first goal is to investigate HT cycle performance concerning turbine power output, thermal efficiency and exergy efficiency under different heat source temperatures and turbine inlet pressures. The second goal is to measure the heat transfer rate from the HT cycle to the LT cycle under different heat source temperatures and heat exchanger inlet pressures. The pinch point temperature difference (PPTD) was studied for various conditions to explore the temperature profiles and heat exchanger characteristics. These investigations provide sufficient knowledge for the optimization of future system operation with various combinations of working fluids.

\section{System description}

The investigated cascaded two-ORC test rig was designed and set up in practice at the University of Paderborn [29]. A schematic of this system is displayed in Fig. 1 and its basic components are listed in Table 1. The test rig contained two essential cycles, the HT cycle and the LT cycle. Heat was supplied by four electrical heaters with an adjustable temperature. Electrical heaters allow for simple control and regulation and are benign with respect to safety and hazard requirements. Furthermore, electrical heaters can be sources over a wide range of temperature [48]. In addition to the two working cycles, the test rig had four supporting cycles. The heating cycle (HC) contained a heat transfer fluid (Therminol 66) which was thermostated by electrical heaters to supply heat to the HT cycle. The mass flow rate of Therminol 66 in the HC was controlled via the rotational frequency of the radial pump M0. The temperature of the HC was controlled via a fully adjustable thyristor-controlled heater (TCH), while three power contactor heaters (PCH) were in use as well. The temperature of Therminol 66 was raised by the flow heaters up to a maximum temperature of $623 \mathrm{~K}$ to avoid its thermal decomposition. Cyclopentane was employed as a working fluid in the HT cycle, while the working fluid in the LT cycle was varied, i.e. propane, butane and pentane. The HT cycle consisted of the essential components of the Rankine cycle, i.e. centrifugal radial turbine coupled to a generator, condenser, plate and shell heat exchanger (as an evaporator) as well as a progressive cavity pump. The LT cycle consisted of the same elements, but the turbine was substituted by a manually adjustable throttle. Fig. 2 shows the cascaded two-ORC system and the basic components of the HC, HT and LT cycles.

In the HT cycle, cyclopentane was compressed by the progressive cavity pump M1, was then heated up and evaporated in the first heat exchanger (HE1), followed by the expansion in the turbine. Because cyclopentane was subsequently still at a high temperature, its residual 
heat was employed to drive the LT cycle. In the LT cycle, the working fluid was heated up in the second heat exchanger (HE2) and expanded through the throttle. Its residual heat was not used further because the according temperature was low. Therefore, the working fluid was condensed via heat discharge to the environment to reach its initial state.

The HE2 is the connection and the main component for the heat transfer between the HT cycle and the LT cycle. Therefore, it was important to explore the performance of the HE2 under different process conditions. The system performance concerning turbine power output, thermal efficiency, exergy efficiency and the heat transfer between the two cycles was investigated under different operational conditions. The long-term target of the experimental investigations is to achieve a maximum exergetic utilization of the heat source and the system optimization for future operation. The heat source temperature, turbine inlet pressure (TIP) and the mass flow rate were varied to investigate the HT cycle's system performance. In contrast, the LT cycle was examined by varying the HE2 inlet pressure for a wide range of heat source temperature.

Temperature, pressure and mass flow rate sensors were located at the inlet and outlet of the components to measure the thermodynamic states and process parameters of the cascaded two-ORC system. Parameter selection to improve only the turbine power output of the HT cycle may have a negative effect on the performance of the LT cycle and the overall system. Optimization of HT cycle parameters has a significant influence on the LT cycle's inlet parameters, which are equal to the outlet conditions of the HT cycle. Thermal and exergy efficiency are suitable criteria for rating the system performance. Thermal efficiency gives the percentage of the heat input being converted into turbine power output. In contrast, the exergy efficiency is an indicator for efficient utilization of the given heat source. Moreover, higher exergy efficiency refers to higher energy quality utilized in the system [29,49].

The heat source temperature and TIP were selected as independent variables to investigate turbine power output, thermal efficiency and exergy efficiency as dependent variables of the HT cycle. The turbine power output is notably dependent on the mass flow rate and the enthalpy difference across the turbine. Thermal and exergy efficiencies may not depend directly on the heat source temperature and TIP, but these two parameters directly affect the net power and input heat flow amount. The thermal efficiency depends on the net power and input heat flow, while thermal exergy depends on two parameters, i.e. net power and exergy flow input. In the LT cycle, heat source temperature and the HE2 inlet pressure were selected as independent variables to investigate the heat transfer rate between the HT cycle and the LT cycle. 
All measurements represent average values of temperature and pressure at each state point. The basic sensors of the cascaded two-ORC system are listed in Table 2.

\section{Thermodynamic analysis}

The expressions and equations employed to define the performance of different operation modes of the cascaded two-ORC system are discussed in the following. In this thermodynamic analysis, the equations were built on the assumptions that there is no significant pressure drop in heat exchangers, condensers or tubes and that the turbine does not exchange heat with the environment. These assumptions are standard practice in the literature. They have also been validated in preceding work of our group and with experimental investigations [44-47].

In the HC, the flow heaters supply Therminol 66 with the heat flow

$\dot{Q}_{H C}=\dot{m}_{H C} \cdot c_{p} \cdot\left(T_{2}-T_{1}\right)$

where $T_{1}$ and $T_{2}$ are temperatures of Therminol 66 at the inlet and outlet of HE1, respectively.

The heat flow $\dot{Q}_{H C}$ into the heating cycle is equal to the heat flow driving the HT

cycle

$\dot{Q}_{H C}=\dot{Q}_{H E, 1}=\dot{m}_{H T} \cdot\left(h_{4}-h_{3}\right)$

where $\dot{m}_{H T}$ is the mass flow rate of cyclopentane in the HT cycle, $h_{3}$ and $h_{4}$ are cyclopentane enthalpies at the inlet and outlet of the heat exchanger HE1, respectively.

The turbine power output is

$\dot{W}_{H T}^{T}=\dot{m}_{H T} \cdot\left(h_{4}-h_{5}\right)$

where $h_{4}$ and $h_{5}$ are cyclopentane enthalpies at the inlet and outlet of the turbine, respectively.

After the expansion, cyclopentane was cooled before entering the pump. The heat transferred via the condenser is given by

$\dot{Q}_{C 1}=\dot{m}_{H T} \cdot\left(h_{6}-h_{7}\right)$

where $h_{6}$ and $h_{7}$ are cyclopentane enthalpies at the inlet and outlet of the condenser C1, respectively.

The work of the pump was calculated by

$\dot{W}_{H T}^{P}=\dot{m}_{H T} \cdot\left(h_{3}-h_{7}\right)$

where $h_{7}$ and $h_{3}$ are cyclopentane enthalpies at the inlet and outlet of the pump M1, respectively. 
The thermal efficiency of the HT cycle was calculated as the ratio of net power to heat flow input

$\eta_{t h, H T}=\frac{\dot{W}_{n e t}}{\dot{Q}_{H C}}$

where $\dot{W}_{n e t}=\dot{W}_{H T}^{T}-\dot{W}_{H T}^{P}$.

The exergy efficiency of the HT cycle was calculated as the ratio of net power to exergy flow input

$\eta_{\text {ex,HT }}=\frac{\dot{W}_{\text {net }}}{\dot{E}_{\text {in }}}$

Therein, $\dot{E}_{\text {in }}$ is the exergy flow from the heat source, which was calculated by

$\dot{E}_{i n}=\dot{m}_{H T}\left[\left(h_{4}-h_{3}\right)-T_{0}\left(s_{4}-s_{3}\right)\right]$

where $T_{0}$ is the ambient temperature, $h_{3}$ and $h_{4}$ are cyclopentane enthalpies at the inlet and outlet of HE1, respectively, while $s_{3}$ and $s_{4}$ are the corresponding entropies.

The turbine efficiency of the HT cycle can be calculated by

$\eta_{T}=\frac{h_{4}-h_{5}}{h_{4}-h_{5 s}}$

where $h_{5 s}$ is the enthalpy of cyclopentane at the outlet of a hypothetic isentropic turbine.

The heat flow through the heat exchanger HE2 was calculated by

$\dot{Q}_{H E, 2}=\dot{m}_{L T} \cdot\left(h_{9}-h_{8}\right)$

where $\dot{m}_{L T}$ is the mass flow rate of the working fluid in the LT cycle, while $h_{8}$ and $h_{9}$ are its enthalpies at the inlet and outlet.

The energy balance of condenser $\mathrm{C}_{2}$ is

$\dot{Q}_{C 2}=\dot{m}_{L T} \cdot\left(h_{10}-h_{11}\right)$

where $h_{10}$ and $h_{11}$ are the working fluid enthalpies at the inlet and outlet of the condenser C2, respectively.

The work of the pump was calculated by

$\dot{W}_{L T}^{P}=\dot{m}_{L T} \cdot\left(h_{8}-h_{11}\right)$

where $h_{11}$ and $h_{8}$ are the working fluid enthalpies at the inlet and outlet of the pump M2, respectively. 


\section{Selection of working fluids}

The selection of working fluids is the most significant key to the performance of ORC cycles. There are many categories of working fluids for ORC systems, which differ considerably from each other in terms of their thermo-physical properties.

Generally, working fluids are divided according to the slope of their saturated vapor line in the temperature-entropy diagram: A positive slope refers to dry fluids, a negative slope refers to wet fluids, while a nearly vertical slope refers to isentropic fluids. Isentropic and dry working fluids are favored in ORC systems because they cannot condense in the turbine [30].

In this work, three dry fluids (butane, pentane and cyclopentane) and one wet fluid (propane) were investigated. The advantages of these hydrocarbons are their low price, environmental friendliness (low GWP and ODP) and thermodynamic attractiveness. The disadvantages are mainly safety related because all of these fluids are very combustible.

The selection of the working fluids was based on their thermodynamic properties, which were calculated with REFPORP 9.0 [31]. The selection was also based on the experimental and simulation results of references [10,17,18,32-38]. Table 3 presents the basic properties of these working fluids. Cyclopentane, that has the highest critical temperature, was selected for the HT cycle, while propane, butane or pentane were alternatively selected for the LT cycle. $40 \mathrm{~kg}$ of cyclopentane was used in the HT cycle, while about $20 \mathrm{~kg}$ of working fluid was used in the LT cycle.

\section{Operational conditions of the experiments}

Different parameters were investigated to assess the system performance. The HT cycle performance considering turbine power output, exergy efficiency, thermal efficiency, enthalpy difference and turbine efficiency was investigated under different conditions. Under condition 1, the HT cycle performance was studied for a heat source temperature from $453 \mathrm{~K}$ to $533 \mathrm{~K}$ at $10 \mathrm{~K}$ intervals. The maximum heat source temperature was limited to the critical temperature of cyclopentane due to safety considerations. Under condition 2, the heat source temperature was kept constant at $533 \mathrm{~K}$ (the maximum temperature under condition 1), while TIP was varied from 2.0 MPa to 3.0 MPa.

The LT cycle was driven by the residual heat flow from the HT cycle so that its output represents the input of the LT cycle and the overall performance depends on the amount of heat flow transferred between the cycles. The influence of the HT cycle on the LT cycle was investigated by looking at the heat transfer between the two cycles. For that purpose, two 
additional conditions were investigated. Under condition 3, the heat source temperature was varied from $453 \mathrm{~K}$ to $533 \mathrm{~K}$. Under condition 4, the heat source temperature was kept constant at $503 \mathrm{~K}$ and $533 \mathrm{~K}$, while the heat transfer was measured for different HE2 inlet pressures. Moreover, the PPTD, which is one of the most important factors affecting the heat transfer, was investigated for different conditions in HE1 and HE2. Under conditions 1 and 2, the PPTD was investigated at points where the maximum turbine power output was achieved. Under conditions 3 and 4, the PPTD was investigated where the largest amount of heat was transferred from the HT cycle to the LT cycle for each working fluid. The HE2 is the device for the heat transfer between the HT cycle and the LT cycle. Therefore, it was important to explore its performance under different process conditions. Basic parameters and operational conditions of the present two-ORC system are listed in Table 4. The selected operational conditions and different parameters are related to the thermo-physical properties of working fluids and the design aspects of various components of the cascaded two-ORC system.

\section{Results and discussion}

The heat source consisted of four electrical flow heaters in the HC cycle with a maximum power of $158 \mathrm{~kW}$ in total. These heaters allowed for adjusting the heat source temperature, both manually and with automatic controllers. The heat flow amount during the experiments was varied by means of the temperature and mass flow rate of Therminol 66 in the HC cycle. The cascaded two-ORC system was studied for heat source temperatures in the range between 453 $\mathrm{K}$ and $533 \mathrm{~K}$ and the TIP was varied between 2.0 MPa and 3.0 MPa. The impact of these important parameters is discussed for each cycle.

\subsection{Effects of heat source temperature on the HT cycle performance (condition 1)}

The first step was to study the impact of the heat source temperature on the cascaded two-ORC system performance. Thermal efficiency, turbine power output and exergy efficiency were investigated for different heat source temperatures. The mass flow rate of cyclopentane was thereby also varied from $0.08 \mathrm{~kg} / \mathrm{s}$ to $0.12 \mathrm{~kg} / \mathrm{s}$. The maximum heat source temperature was selected to keep the turbine inlet temperature below the critical temperature of cyclopentane to avoid supercritical states.

For the variation between $453 \mathrm{~K}$ and $533 \mathrm{~K}$, the impact of heat source temperature on the turbine power output can be seen in Fig. 3 (a). As the heat source temperature increases, the turbine power output rises. A comparison between the three configurations shows that the 
maximum turbine power output was $4.64 \mathrm{~kW}$ at a heat source temperature of $533 \mathrm{~K}$ and a mass flow rate of $0.12 \mathrm{~kg} / \mathrm{s}$. Furthermore, the turbine power output varied from $0.65 \mathrm{~kW}$ to $2.86 \mathrm{~kW}$ at a mass flow rate of $0.08 \mathrm{~kg} / \mathrm{s}$, while it varied between $1.09 \mathrm{~kW}$ to $3.64 \mathrm{~kW}$ at a mass flow rate of $0.10 \mathrm{~kg} / \mathrm{s}$. The observed increase of turbine power output can be explained by the fact that with the rise of the heat source temperature, the ratio between inlet and outlet pressure of the turbine increases. This means that the increasing heat source temperature increased both inlet and outlet pressure of the turbine. Nevertheless, the increasing rate of the inlet pressure outweighs the increasing rate of the outlet pressure. This leads to a larger enthalpy difference across the turbine, as shown in Fig.4 (a), so that its power output increases. The enthalpy difference across the turbine increases for all three working fluid mass flow rates with rising heat source temperature. The results indicate that the impact of enthalpy drop across the turbine on the turbine power output is more significant than that of mass flow rate.

The thermal efficiency as a function of the heat source temperature is depicted in Fig. 3 (b). When the heat source temperature rises from $453 \mathrm{~K}$ to $533 \mathrm{~K}$ for a cyclopentane mass flow rate of $0.08 \mathrm{~kg} / \mathrm{s}$, the thermal efficiency increases from $1.84 \%$ to $4.80 \%$. At a mass flow rate of 0.10 $\mathrm{kg} / \mathrm{s}$, the thermal efficiency rises from $2 \%$ to $5.3 \%$. The maximum thermal efficiency in this experiment was $5.50 \%$ at a temperature of $533 \mathrm{~K}$, where the mass flow rate was $0.12 \mathrm{~kg} / \mathrm{s}$. The increase of thermal efficiency with heat source temperature indicates that the increasing net power rate is higher than that of the heat flow input to the HT cycle so that the thermal efficiency increases gradually.

The variation of the exergy efficiency as a function of heat source temperature for different mass flow rates of cyclopentane is shown in Fig. 3 (c). As expected, the three investigated cases ( $\dot{m}=0.08,0.10$ and $0.12 \mathrm{~kg} / \mathrm{s}$ ) show an increasing trend. The maximum exergy efficiency of $20.2 \%$ was obtained for a mass flow rate of $0.12 \mathrm{~kg} / \mathrm{s}$ and a heat source temperature of $533 \mathrm{~K}$. It was throughout observed that the exergy efficiency rises with the heat source temperature. The main reason is that the net power increases with heat source temperature and the increasing rate is higher than that of exergy flow input.

The variation of the turbine efficiency with heat source temperature is shown in Fig. 4 (b). The results demonstrate that the turbine efficiency rises with heat source temperature, which can be related to the increase of enthalpy difference across the turbine. As seen in Fig. 4 (a), the enthalpy difference increased with the heat source temperature leading to a higher turbine efficiency. The maximum measured turbine efficiency was $39.12 \%$ at a heat source temperature of $533 \mathrm{~K}$. 


\subsection{Effects of TIP on the HT cycle performance (condition 2)}

In this section, the impact of the TIP on the cascaded two-ORC system performance was studied. The heat source temperature was kept constant at $533 \mathrm{~K}$, where the highest HT cycle performance was achieved under condition 1 . The mass flow rate of cyclopentane was varied from $0.12 \mathrm{~kg} / \mathrm{s}$ to $0.15 \mathrm{~kg} / \mathrm{s}$ by adjusting the rotational frequency of the pump M1. The inlet pressure was again kept throughout below the critical pressure of cyclopentane to avoid supercritical states.

Fig. 5 shows the impact of the TIP on the turbine output power, thermal and exergy efficiencies and demonstrates the variation of turbine power output with TIP. When the TIP rises from 2.0 MPa to 3.0 MPa, the turbine power output increases slightly from $3.18 \mathrm{~kW}$ to $4.92 \mathrm{~kW}$ for a mass flow rate between $0.12 \mathrm{~kg} / \mathrm{s}$ and $0.15 \mathrm{~kg} / \mathrm{s}$. However, the turbine power output is related to turbine inlet and outlet pressure and both were increased during this experiment. The higher pressure ratio in this test entails a larger enthalpy drop across the turbine and more power output was generated as depicted in Fig. 6. When the TIP increases, the enthalpy difference across the turbine rises as well and causes an increase of the turbine power output.

The variation of the thermal efficiency versus TIP is also shown in Fig. 5. It can be concluded that the thermal efficiency increased slightly from $4.17 \%$ to $4.60 \%$ as the TIP increased from 2.0 MPa to 3.0 MPa. The rise of the TIP led to a larger heat flow transferred from the HC cycle to the HT cycle, while pump work increased as well. However, the increasing rate of net power slightly outweighs that of the increasing rate of the heat flow input $\dot{Q}_{H C}$, which led to a slight increase in thermal efficiency according to equation (6).

The influence of the TIP on exergy efficiency is also shown in Fig. 5. It can be noted that the exergy efficiency increases with TIP. When the TIP increases from 2.0 MPa to 3.0 MPa, the exergy efficiency rises from $16.3 \%$ to $17.11 \%$. This increasing trend is expected, as the TIP increases, the enthalpy difference across the turbine increases, which results in a higher turbine power output and a better exergy efficiency. In other words, the ratio of net power to exergy flow input $\dot{E}_{\text {in }}$ increases with increasing TIP.

Fig. 6 displays the turbine efficiency and the enthalpy difference across the turbine upon variation of the TIP. As the TIP increased, the enthalpy difference rises from $26.87 \mathrm{~kJ} / \mathrm{kg}$ to $32.82 \mathrm{~kJ} / \mathrm{kg}$, while the turbine efficiency increased from $29.1 \%$ to $31.6 \%$. Generally, by comparing condition 1 with condition 2, the highest turbine power output was gained under condition 2 at a heat source temperature of $533 \mathrm{~K}$ and a TIP of $3.0 \mathrm{MPa}$, which is due to the positive impact of the higher TIP. The thermal and exergy efficiencies under condition 2 were 
lower than under condition 1. This can be explained as follows: Increasing the TIP required more pump work during the experiment. Moreover, the HT cycle absorbed more heat from the HC cycle under condition 2. This results in a lower thermal efficiency, which is related to turbine power output, pump work and heat flow input. Increasing the pump work reduced the increasing rate of the net power which directly affected the exergy efficiency. The system achieved the maximum thermal and exergy efficiencies under condition 1, where the heat source temperature was $533 \mathrm{~K}$ and the mass flow rate $0.12 \mathrm{~kg} / \mathrm{s}$. In contrast, the maximum turbine power output was obtained under condition 2, where the heat source was $533 \mathrm{~K}$, TIP 3.0 MPa and the mass flow rate $0.15 \mathrm{~kg} / \mathrm{s}$. Solely turbine power output does not reflect system performance improvement because focusing on selected parameters may have a negative impact on the overall system performance. In the case of a two-ORC system, it is better to adopt thermal and exergy efficiencies as criteria for the system performance [10].

Figs. 7 depict the heat transfer and temperature profiles in HE1 under conditions 1 and 2 at operating parameters where the maximum turbine power output was achieved. State points 1 and 2 refer to the inlet and outlet of Therminol 66 in the HC cycle, respectively. Moreover, HE1 was divided for both conditions into three sections: preheating (3-3a), evaporation (3a-3b) and superheating (3b-4). Fig. 7 also shows PPTD under conditions 1 and 2, which is the minimum temperature difference between Therminol 66 and cyclopentane in HE1. The PPTD was calculated by the following equations according to Figs. 2 and 7.

Under condition 1 , the PPTD $=T_{1}-T_{4}$

PPTD under condition 2:

$\dot{Q}_{3-3 a}=-\dot{Q}_{2-1 a}$

$\dot{Q}_{3-3 a}=\dot{m}_{H T} \cdot\left(h_{3 a}-h_{3}\right)$

$\dot{Q}_{2-1 a}=\dot{m}_{H C} \cdot c_{p} \cdot\left(T_{2}-T_{1 a}\right)$

$T_{1 a}=\frac{\dot{Q}_{2-1 a}}{\dot{m}_{H C} \cdot c_{p}}+T_{2}$

$\mathrm{PPDT}=T_{1 a}-T_{3 a}$

The heat flow-temperature diagram gives a clearer picture of the heat exchanger's performance and the matching between Therminol 66 and the cyclopentane during evaporation for optimal exergy utilization of the heat source temperature. Furthermore, an optimal PPTD 
during the heat transfer from the heat source to the HC cycle and to the HT cycle may reduce exergy losses.

Fig. 7 (a) represents the operation parameters where the maximum turbine power output of $4.6 \mathrm{~kW}$ was gained under condition 1 . At a heat source temperature of $533 \mathrm{~K}$, a heat flow of $83 \mathrm{~kW}$ was transferred from the HC cycle to the HT cycle. The transferred heat flow was utilized for preheating, evaporating and superheating a mass flow rate of $0.12 \mathrm{~kg} / \mathrm{s}$ of cyclopentane from state point 3 to state point 4 . The PPTD under condition 1 was $30 \mathrm{~K}$ and was located at the HE1 outlet.

Fig. 7 (b) depicts the operation parameters where the maximum turbine power output of $4.9 \mathrm{~kW}$ was yielded under condition 2. At a heat source temperature of $533 \mathrm{~K}$, the HC cycle transferred a heat flow of $99.82 \mathrm{~kW}$ to the LT cycle. The heat flow was employed for preheating, evaporating and superheating $0.15 \mathrm{~kg} / \mathrm{s}$ of cyclopentane from state point 3 to state point 4 . The PPTD was $23 \mathrm{~K}$ and was located at the beginning of the evaporation section (3a-3b). However, the location of the PPTD depends on the temperature profiles in HE1, the amount of the heat flow from the HC cycle and system performance. The PPTD is a significant factor affecting the heat flow from the HC cycle to the HT cycle. Moreover, the PPTD is related to the heat exchange surface area and the performance of the heat source fluid. Optimal PPTD lead to small exergy losses between the two streams in the HE1, but require a large heat exchange surface area to transfer the heat flow from Therminol 66 to cyclopentane in the HT cycle. The variation in the PPTD values in Fig. 7 (a) and (b) is due to several factors, which are the difference in mass flow, the amount of transferred heat flow and the inlet and outlet temperature of HE1 in both cases. At the highest heat source temperature of $533 \mathrm{~K}$, the heat flow under condition 2 was higher than that under condition 1 , but the thermal and exergy efficiencies were lower. That means the amount of transferred heat flow that was converted into useful work and the utilization of source heat temperature under the condition 2 was lower than that under condition 1.

\subsection{Effects of heat source temperature on the LT cycle performance (condition 3)}

During the present experiments, three working fluids, i.e. propane, butane and pentane, were used to investigate the heat transfer from the HT cycle to the LT cycle. The throttle in the LT cycle was manually adjusted to provide an appropriate expansion process according to the properties of the working fluids and the operational conditions of the system.

Since the present test rig was designed as a cascaded two-ORC system, the second heat exchanger HE2 was a crucial component in this experiment for the heat transfer between the 
HT cycle and the LT cycle. It was important to investigate the different parameters and operational conditions related to HE2 characteristics, such as inlet temperature, mass flow rates and HE2 inlet pressure.

Fig. 8 shows a comparison of the heat transfer rate form the HT cycle to the LT cycle for the three organic fluids. The mass flow rate of the working fluids in the LT cycle was varied from $0.030 \mathrm{~kg} / \mathrm{s}$ to $0.035 \mathrm{~kg} / \mathrm{s}$. The heat source temperature in the HC cycle for pentane and butane ranged from $453 \mathrm{~K}$ to $533 \mathrm{~K}$ in increments of $10 \mathrm{~K}$, while the heat source temperature for propane was in a smaller range from $453 \mathrm{~K}$ to $503 \mathrm{~K}$ because of its low critical temperature (369.89 K). A comparison between the three configurations shows that among the three working fluids, pentane is the one with the highest transferred heat flow rates. The maximum transferred heat flow to the LT cycle was $21 \mathrm{~kW}$, obtained at a mass flow rate of $0.035 \mathrm{~kg} / \mathrm{s}$ and a heat source temperature of $533 \mathrm{~K}$. Because the heat source temperature was not fixed, the heat absorbed by the LT cycle varied and rose with an increase of the heat source temperature. As the heat source temperature raised from $453 \mathrm{~K}$ to $503 \mathrm{~K}$, the transferred heat flow grew from $13.8 \mathrm{~kW}$ to $16.82 \mathrm{~kW}$ in case of propane and from $14.90 \mathrm{~kW}$ to $19.30 \mathrm{~kW}$ for butane, while the according numbers were $16.35 \mathrm{~kW}$ to $21.00 \mathrm{~kW}$ for pentane. Generally, the amount of transferred heat flow depends on the thermo-physical properties of the working fluids and the process parameters of the LT cycle, such as temperature and the mass flow rate. As the amount of transferred heat flow increased with the rising heat source temperature, it was primarily expected that the maximum transferred heat flow in the case of propane is lower. This is primarily because the maximum heat source temperature was lower than that of pentane and butane.

\subsection{Effects of HE2 inlet pressure on the LT cycle performance (condition 4)}

This test was carried out at a heat source temperature of $533 \mathrm{~K}$, where the highest amount of heat flow was transferred from the HT cycle to the LT cycle under condition 3 by using pentane and butane as working fluids. The heat source temperature for propane was $503 \mathrm{~K}$ because of its low critical temperature. The mass flow rate of the working fluids was varied in the range from $0.035 \mathrm{~kg} / \mathrm{s}$ to $0.048 \mathrm{~kg} / \mathrm{s}$. The variation of HE2 inlet pressure and the heat transfer to the LT cycle can be seen in Fig. 9. For all working fluids, an increase of the HE2 inlet pressure led to a gradual increase of the heat transfer from the HT cycle to the LT cycle. The transferred heat flow for propane increased from $14.88 \mathrm{~kW}$ to $19.30 \mathrm{~kW}$ at a heat source temperature of $503 \mathrm{~K}$, as the HE2 inlet pressure rises in the limited range from 3.2 MPa to 3.6 MPa to avoid critical conditions. Moreover, when using butane as a working fluid, the HE2 inlet pressure 
varied from 2.2 MPa to 2.7 MPa, while the transferred heat flow increased from $16.21 \mathrm{~kW}$ to $21.00 \mathrm{~kW}$. The maximum achievable heat transfer during these experiments was $23 \mathrm{~kW}$ by employing pentane as working fluid, when the HE2 inlet pressure was raised from 1.2 MPa to 1.7 MPa. As mentioned earlier, it was expected that the amount of transferred heat flow in the case of propane is lower since the maximum heat source temperature is less than that in the case of pentane or butane.

The heat transfer rate values under condition 4 are higher than under condition 3 for all working fluids. The main reason is that the variation of the mass flow rate of working fluids under condition 4 was larger than that under condition 3. For all working fluids under condition 4, the mass flow rate varied from $0.035 \mathrm{~kg} / \mathrm{s}$ to $0.048 \mathrm{~kg} / \mathrm{s}$ and led to an increase of the HE2 inlet pressure and an increase of the absorbed heat flow rate from the HT cycle. Furthermore, the HE2 inlet pressure had a more significant effect on the heat transfer rate values than the heat source temperature variation. Since the LT cycle employed a throttle as an expansion device, it was important to explore the heat transfer between the two cycles and the PPTD to examine the performance of HE2, which is helpful for designing the LT cycle's turbine.

Fig. 10 shows the temperature profile, heat flow and PPTD at the operating condition where the maximum amount a heat flow was transferred from the HT cycle to the LT cycle under condition 3 in the HE2. The PPTD under these conditions was calculated by

$\dot{Q}_{9-8 a}=-\dot{Q}_{5-5 a}$

$\dot{Q}_{9-8 a}=\dot{m}_{L T} \cdot\left(h_{9}-h_{8 a}\right)$

$\dot{Q}_{5-5 a}=\dot{m}_{H T} \cdot c_{p} \cdot\left(T_{5}-T_{5 a}\right)$

$T_{5 a}=\frac{\dot{Q}_{5-5 a}}{\dot{m}_{H T} \cdot c_{p}}+T_{5}$

$\mathrm{PPDT}=T_{5 a}-T_{8 a}$

Fig. 10 (a) shows operating parameters where the maximum heat flow was transferred under condition 3 in the HE2 by using pentane as a working fluid. At a heat source temperature of $533 \mathrm{~K}$ and a mass flow rate of $0.12 \mathrm{~kg} / \mathrm{s}$, cyclopentane from the HT cycle supplied the LT cycle a heat flow of $21 \mathrm{~kW}$. The absorbed heat was utilized for preheating, evaporating and superheating a mass flow rate of $0.035 \mathrm{~kg} / \mathrm{s}$ of pentane from state point 8 to state point 9 . The PPTD was $19 \mathrm{~K}$ and was located at the beginning of the evaporation section (8a-8b).

Fig. 10 (b) shows the temperature profile, heat flow and PPTD where the maximum heat flow absorbed by butane under condition 3 in the HE2. A heat flow of $19.3 \mathrm{~kW}$ was 
transferred from the HT cycle to the LT cycle. The absorbed heat was used for preheating, evaporating and superheating $0.035 \mathrm{~kg} / \mathrm{s}$ of butane from the state point 8 to state point 9 . The PPTD was $25 \mathrm{~K}$ and located at the beginning of evaporation section (8a-8b).

Fig. 10 (c) shows the same properties when propane was employed as a working fluid. The mass flow rate of cyclopentane was raised to $0.12 \mathrm{~kg} / \mathrm{s}$ at a heat source temperature of 503 K. A heat flow of $16.82 \mathrm{~kW}$ was transferred from the HT cycle to the LT cycle for preheating, evaporating and superheating $0.04 \mathrm{~kg} / \mathrm{s}$ of propane. The PPTD was $33 \mathrm{~K}$ and was located at the beginning of the evaporation section (8a-8b).

Fig. 11 shows the heat transfer, temperature profiles and the PPTD in HE2 at operating parameters where the maximum heat flow was transferred from the HT cycle to the LT cycle under condition 4. In the HT cycle, the mass flow rate of cyclopentane was raised up to 0.12 $\mathrm{kg} / \mathrm{s}$ at a heat source temperature of $533 \mathrm{~K}$. A heat flow of $23.00 \mathrm{~kW}$ was transferred to the LT cycle from the HT cycle. The heat flow was utilized for preheating, evaporating and superheating $0.04 \mathrm{~kg} / \mathrm{s}$ of pentane at a pressure of $1.7 \mathrm{MPa}$ from state point 8 to state point 9 as shown in Fig. 11 (a). The PPTD was $13 \mathrm{~K}$ and was located at the beginning of the evaporation section (8a-8b).

Fig. 11 (b) shows the same properties in HE2 under condition 4 by using butane as a working fluid. A heat flow of $21 \mathrm{~kW}$ was transferred to the LT cycle for preheating, evaporating and superheating $0.04 \mathrm{~kg} / \mathrm{s}$ of butane at a heat source temperature of $533 \mathrm{~K}$ and a pressure of 2.7 MPa. The PPTD was $21 \mathrm{~K}$ and located at the beginning of the evaporation section (8a-8b).

Fig. 11 (c) is analogous for propane as a working fluid. At a heat source temperature of $503 \mathrm{~K}$, propane was pressurized to 3.6 MPa. A heat flow of $19.3 \mathrm{~kW}$ was transferred to the LT cycle for preheatinging, evaporating and superheat a mass flow rate of $0.048 \mathrm{~kg} / \mathrm{s}$ of propane from state point 8 to state point 9. The PPTD was $30 \mathrm{~K}$ and located at the beginning of the evaporation section (8a-8b).

The PPTD is an important factor for the heat exchanger effectiveness and is related to the overall system performance. The lower PPTD led to an increase of the absorbed heat flow from the HT cycle. Moreover, the amount of transferred heat flow to the LT cycle and the PPTD location depend on the HT cycle performance, the temperature profile of the HE2, thermophysical properties of the working fluid and process parameters of the LT cycle. By comparing Figs. 10 and 11, the PPTD values under condition 4 are lower than under condition 3 for all working fluids and the maximum transferred heat flow for all working fluids is higher than that under condition 3. This variation may be explained as follows: Under condition 4, the mass 
flow rate variation of the working fluids was larger than that under condition 3 . This led to an increase in the absorbed heat flow from the HT cycle, which was higher under condition 4. Therefore, under condition 4, the PPTD values were lower than those under condition 3 in the HE2 for the same working fluids.

\section{Conclusion}

A cascaded two-ORC system was studied experimentally, filling the gap in scientific research with respect to testing the two-ORC system for a wide range of temperatures and pressures. Various parameters were employed to provide practical results that can be used for system improvements and optimization. Cyclopentane was used in the HT cycle, while pentane, butane and propane were alternatively employed as working fluids in the LT cycle. The purpose of this work was to investigate the cascaded two-ORC system performance under different operating parameters. Results were presented for the performance of the HT cycle and the LT cycle for a heat source temperature between $453 \mathrm{~K}$ and $533 \mathrm{~K}$ as well as different values of the mass flow rate and the turbine inlet pressure. The maximum power output of the HT cycle was $4.92 \mathrm{~kW}$ for a heat source temperature of $533 \mathrm{~K}$ and working fluid mass flow rate of $0.15 \mathrm{~kg} / \mathrm{s}$. The maximum thermal efficiency was 5.5\% for a heat source temperature of $533 \mathrm{~K}$ and a mass flow rate of $0.12 \mathrm{~kg} / \mathrm{s}$, while the maximum exergy efficiency was 20.15 \% under the same condition. Since the LT cycle employed a throttle as an expansion device, it was important to explore the heat transfer between the two cycles and the PPTD to examine the performance of HE2. The heat transfer rate between the HT cycle and the LT cycle was examined by employing three working fluids. The results illustrate that part of the residual heat from the HT cycle was absorbed by the working fluid in the LT cycle and the remainder was dissipated by the cooling cycle. Heat transfer measurements showed that the best option among the considered fluids was pentane. The maximum heat transferred to the LT cycle and absorbed by pentane was $23 \mathrm{~kW}$. However, the majority of the heat flow from HT cycle was not transferred to LT cycle. The present experimental results demonstrate that more work is needed to enhance the system performance. The experimental investigations were promising and showed that the two-ORC system is suitable to utilize heat sources under different operational conditions. The present paper is encouraging further experimental and theoretical examinations for clarifying the advantages of cascaded two-ORC systems.

Furthermore, to present the convenience of cascaded two-ORC systems, a new turbine must be designed and built to study the power output, thermal and exergy efficiency of the LT cycle. In addition, the HT cycle performance should be studied for varying working fluids. 


\section{Acknowledgements}

We gratefully acknowledge the German Academic Exchange Service (DAAD) for financial support and the help provided by Dr. Gerhard Herres, University of Paderborn.






\section{References}

[1] B.F. Tchanche, G. Lambrinos, A. Frangoudakis, G. Papadakis, Low-grade heat conversion into power using organic Rankine cycles - A review of various applications, Renew. Sustain. Energy Rev. 15 (2011) 3963-3979. doi:10.1016/j.rser.2011.07.024.

[2] G. Bamorovat Abadi, K.C. Kim, Investigation of organic Rankine cycles with zeotropic mixtures as a working fluid: Advantages and issues, Renew. Sustain. Energy Rev. 73 (2017) 1000-1013. doi:10.1016/j.rser.2017.02.020.

[3] H. Zhai, Q. An, L. Shi, V. Lemort, S. Quoilin, Categorization and analysis of heat sources for organic Rankine cycle systems, Renew. Sustain. Energy Rev. 64 (2016) 790-805. doi:10.1016/j.rser.2016.06.076.

[4] J. Vivian, G. Manente, A. Lazzaretto, A general framework to select working fluid and configuration of ORCs for low-to-medium temperature heat sources, Appl. Energy 156 (2015) 727-746. doi:10.1016/j.apenergy.2015.07.005.

[5] B. Saleh, G. Koglbauer, M. Wendland, J. Fischer, Working fluids for low-temperature organic Rankine cycles, Energy 32 (2007) 1210-1221. doi:10.1016/j.energy.2006.07.001.

[6] J. Bao, L. Zhao, A review of working fluid and expander selections for organic Rankine cycle, Renew. Sustain. Energy Rev. 24 (2013) 325-342. doi:10.1016/j.rser.2013.03.040.

[7] W. Ma, T. Liu, R. Min, M. Li, Effects of physical and chemical properties of working fluids on thermodynamic performances of medium-low temperature organic Rankine cycles (ORCs), Energy Convers. Manag. 171 (2018) 742-749.

doi:10.1016/j.enconman.2018.06.032.

[8] E.H. Wang, H.G. Zhang, B.Y. Fan, M.G. Ouyang, F.Y. Yang, K. Yang, Z. Wang, J. Zhang, F.B. Yang, Parametric analysis of a dual-loop ORC system for waste heat recovery of a diesel engine, Appl. Therm. Eng. 67 (2014) 168-178. doi:10.1016/j.applthermaleng.2014.03.023.

[9] S. Lecompte, H. Huisseune, M. Van Den Broek, B. Vanslambrouck, M. De Paepe, Review of organic Rankine cycle (ORC) architectures for waste heat recovery, Renew. Sustain. Energy Rev. 47 (2015) 448-461. doi:10.1016/j.rser.2015.03.089.

[10] K. Braimakis, S. Karellas, Exergetic optimization of double stage Organic Rankine Cycle (ORC), Energy 149 (2018) 296-313. doi:10.1016/j.energy.2018.02.044.

[11] G. Yu, G. Shu, H. Tian, Y. Huo, W. Zhu, Experimental investigations on a cascaded steam-/organic-Rankine-cycle (RC/ORC) system for waste heat recovery (WHR) from diesel engine, Energy Convers. Manag. 129 (2016) 43-51.

doi:10.1016/j.enconman.2016.10.010.

[12] P. Gang, L. Jing, J. Jie, Design and analysis of a novel low-temperature solar thermal electric system with two-stage collectors and heat storage units, Renew. Energy 36 (2011) 2324-2333. doi:10.1016/j.renene.2011.02.008. 
[13] W. Fu, J. Zhu, T. Li, W. Zhang, J. Li, Comparison of a Kalina cycle based cascade utilization system with an existing organic Rankine cycle based geothermal power system in an oilfield, Appl. Therm. Eng. 58 (2013) 224-233.

doi:10.1016/j.applthermaleng.2013.04.012.

[14] U. Drescher, D. Brüggemann, Fluid selection for the Organic Rankine Cycle (ORC) in biomass power and heat plants, Appl. Therm. Eng. 27 (2007) 223-228.

doi:https://doi.org/10.1016/j.applthermaleng.2006.04.024.

[15] H. Sun, H. Zhu, F. Liu, H. Ding, Simulation and optimization of a novel Rankine power cycle for recovering cold energy from liquefied natural gas using a mixed working fluid, Energy 70 (2014) 317-324. doi:10.1016/j.energy.2014.03.128.

[16] T. Sung, K.C. Kim, Thermodynamic analysis of a novel dual-loop organic Rankine cycle for engine waste heat and LNG cold, Appl. Therm. Eng. 100 (2016) 1031-1041. doi:10.1016/j.applthermaleng.2016.02.102.

[17] M. Mehrpooya, M. Ashouri, A. Mohammadi, Thermoeconomic analysis and optimization of a regenerative two-stage organic Rankine cycle coupled with liquefied natural gas and solar energy, Energy 126 (2017) 899-914.

doi:10.1016/j.energy.2017.03.064.

[18] F. Yang, H. Cho, H. Zhang, J. Zhang, Thermoeconomic multi-objective optimization of a dual loop organic Rankine cycle (ORC) for CNG engine waste heat recovery, Appl. Energy 205 (2017) 1100-1118. doi:https://doi.org/10.1016/j.apenergy.2017.08.127.

[19] G. Kosmadakis, D. Manolakos, S. Kyritsis, G. Papadakis, Comparative thermodynamic study of refrigerants to select the best for use in the high-temperature stage of a twostage organic Rankine cycle for RO desalination, Desalinaion 243 (2009) 74-94. doi:10.1016/j.desal.2008.04.016.

[20] X. Xue, C. Guo, X. Du, L. Yang, Y. Yang, Thermodynamic analysis and optimization of a two-stage organic Rankine cycle for liquefied natural gas cryogenic exergy recovery, Energy. 83 (2015) 778-787. doi:10.1016/j.energy 2015.02.088.

[21] M. Preißinger, F. Heberle, D. Brüggemann, Exergetic analysis of biomass fired doublestage organic rankine cycle (ORC), Proc. 25th Int. Conf. Effic. Cost, Optim. Simul. Energy Convers. Syst. Process. ECOS 2012. 1 (2012) 155-165.

[22] F. Ayachi, E. Boulawz, A. Zoughaib, P. Neveu, ORC optimization for medium grade heat recovery, Energy 68 (2014) 47-56. doi:10.1016/j.energy.2014.01.066.

[23] E. Yun, H. Park, S.Y. Yoon, K.C. Kim, Dual parallel organic Rankine cycle ( ORC ) system for high efficiency waste heat recovery in marine application , Mech. Sci.Tech. 29 (2015) 2509-2515. doi:10.1007/s12206-015-0548-5.

[24] I. Choi, S. Lee, Y. Seo, D. Chang, Analysis and optimization of cascade Rankine cycle for liquefied natural gas cold energy recovery, Energy 61 (2013) 179-195. doi:10.1016/j.energy.2013.08.047.

[25] P. Li, J. Li, G. Pei, J. Ji, A cascade organic Rankine cycle power generation system using hybrid solar energy and liquefied natural gas, Sol. Energy 127 (2016) 136-146. doi:10.1016/j.solener.2016.01.029. 
[26] G. Shu, L. Liu, H. Tian, H. Wei, G. Yu, Parametric and working fluid analysis of a dual-loop organic Rankine cycle (DORC) used in engine waste heat recovery, Appl. Energy. 113 (2014) 1188-1198. doi:10.1016/j.apenergy.2013.08.027.

[27] M. Linnemann, K.P. Priebe, A. Heim, C. Wolff, J. Vrabec, Experimental investigation of a cascaded organic Rankine cycle plant for the utilization of waste heat at high and low temperature levels, Energy Convers. Manag. 205 (2020) 112381. doi:10.1016/j.enconman.2019.112381.

[28] G. Shu, G. Yu, H. Tian, H. Wei, X. Liang, Z. Huang, Multi-approach evaluations of a cascade-Organic Rankine Cycle (C-ORC) system driven by diesel engine waste heat: Part A - Thermodynamic evaluations, Energy Convers. Manag. 108 (2016) 579-595. doi:10.1016/j.enconman.2015.10.084.

[29] F.H. Dubberke, M. Linnemann, W.K. Abbas, E. Baumhögger, K.P. Priebe, M. Roedder, M. Neef, J. Vrabec, Experimental setup of a cascaded two-stage organic Rankine cycle, Appl. Therm. Eng. 131 (2018) 958-964. doi:10.1016/j.applthermaleng.2017.11.137.

[30] P.J. Mago, L.M. Chamra, K. Srinivasan, C. Somayaji, An examination of regenerative organic Rankine cycles using dry fluids, Appl. Therm. Eng. 28 (2008) 998-1007. doi:10.1016/j.applthermaleng.2007.06.025.

[31] E.W. Lemmon, M.L. Huber, M.O. McLinden, Reference fluid thermodynamic and transport properties (REFPROP), version 9.0, in NIST Standard Reference Database 23. National Institute of Standard and Technology, Gaithersburg, MD:2007.

[32] J. Schilling, M. Lampe, J. Gross, A. Bardow, 1-stage CoMT-CAMD: An approach for integrated design of ORC process and working fluid using PC-SAFT, Chem. Eng. Sci. 159 (2017) 217-230. doi:10.1016/j.ces.2016.04.048.

[33] R. Rayegan, Y.X. Tao, A procedure to select working fluids for Solar Organic Rankine Cycles (ORCs), Renew. Energy 36 (2011) 659-670. doi:10.1016/j.renene.2010.07.010.

[34] M.A. Siddiqi, B. Atakan, Alkanes as fluids in Rankine cycles in comparison to water, benzene and toluene, Energy 45 (2012) 256-263. doi:10.1016/j.energy.2012.06.005.

[35] C.M. Invernizzi, P. Iora, G. Manzolini, S. Lasala, Thermal stability of n-pentane, cyclo-pentane and toluene as working fluids in organic Rankine engines, Appl. Therm. Eng. 121 (2017) 172-179. doi:10.1016/j.applthermaleng.2017.04.038.

[36] H. Zhai, L. Shi, Q. An, Influence of working fluid properties on system performance and screen evaluation indicators for geothermal ORC (organic Rankine cycle) system, Energy 74 (2014) 2-11. doi:10.1016/j.energy.2013.12.030.

[37] A. Mahmoudi, M. Fazli, M.R. Morad, A recent review of waste heat recovery by Organic Rankine Cycle, Appl. Therm. Eng. 143 (2018) 660-675. doi:10.1016/j.applthermaleng.2018.07.136.

[38] G. Qiu, Selection of working fluids for micro-CHP systems with ORC, Renew. Energy 48 (2012) 565-570. doi:10.1016/j.renene.2012.06.006.

[39] E.W. Lemmon, M.O. McLinden, W. Wagner, Thermodynamic properties of propane. III. A reference equation of state for temperatures from the melting line to $650 \mathrm{~K}$ and pressures up to $1000 \mathrm{MPa}$, J. Chem. Eng. Data 54 (2009) 3141-3180. doi:10.1021/je900217v. 
[40] D. Bücker, W. Wagner, Reference equations of state for the thermodynamic properties of fluid phase n-butane and isobutane, J. Phys. Chem. Ref. Data 35 (2006) 929-1019. doi:10.1063/1.1901687.

[41] C.M. Invernizzi, P. Iora, G. Manzolini, S. Lasala, Thermal stability of n-pentane, cyclo-pentane and toluene as working fluids in organic Rankine engines, Appl. Therm. Eng. 121 (2017) 172-179. doi:10.1016/j.applthermaleng.2017.04.038.

[42] H. Gedanitz, M.J. Davila, E.W. Lemmon, Speed of sound measurements and a fundamental equation of state for cyclopentane, J. Chem. Eng. Data 60 (2015) 13311337. doi:10.1021/je5010164.

[43] E. Ntavou, G. Kosmadakis, D. Manolakos, G. Papadakis, D. Papantonis, Experimental testing of a small-scale two stage Organic Rankine Cycle engine operating at low temperature, Energy 141 (2017) 869-879. doi:10.1016/j.energy.2017.09.127.

[44] E. Galloni, G. Fontana, S. Staccone, Design and experimental analysis of a mini ORC (organic Rankine cycle ) power plant based on R245fa working fluid, Energy 90 (2015) 768-775. doi:10.1016/j.energy.2015.07.104.

[45] C.J. Butcher, B. V. Reddy, Second law analysis of a waste heat recovery based power generation system, Int. J. Heat Mass Transf. 50 (2007) 2355-2363. doi:10.1016/j.ijheatmasstransfer.2006.10.047.

[46] T. Sung, E. Yun, H.D. Kim, S.Y. Yoon, B.S. Choi, K. Kim, J. Kim, Y.B. Jung, K.C. Kim, Performance characteristics of a 200-kW organic Rankine cycle system in a steel processing plant, Appl. Energy 183 (2016) 623-635. doi:10.1016/j.apenergy.2016.09.018.

[47] N. Zhou, X. Wang, Z. Chen, Z. Wang, Experimental study on Organic Rankine Cycle for waste heat recovery from low-temperature flue gas, Energy 55 (2013) 216-225. doi:10.1016/j.energy.2013.03.047.

[48] P. Wang, P. Zhao, Y. Lai, J. Wang, Y. Dai, Performance comparison of different combined heat and compressed air energy storage systems integrated with organic Rankine cycle, Int. J. Energy Res. 43 (2019) 8410-8425. doi:10.1002/er.4839.

[49] S. Safarian, F. Aramoun, Energy and exergy assessments of modified Organic Rankine Cycles (ORCs), Energy Reports. 1 (2015) 1-7. doi:10.1016/j.egyr.2014.10.003. 


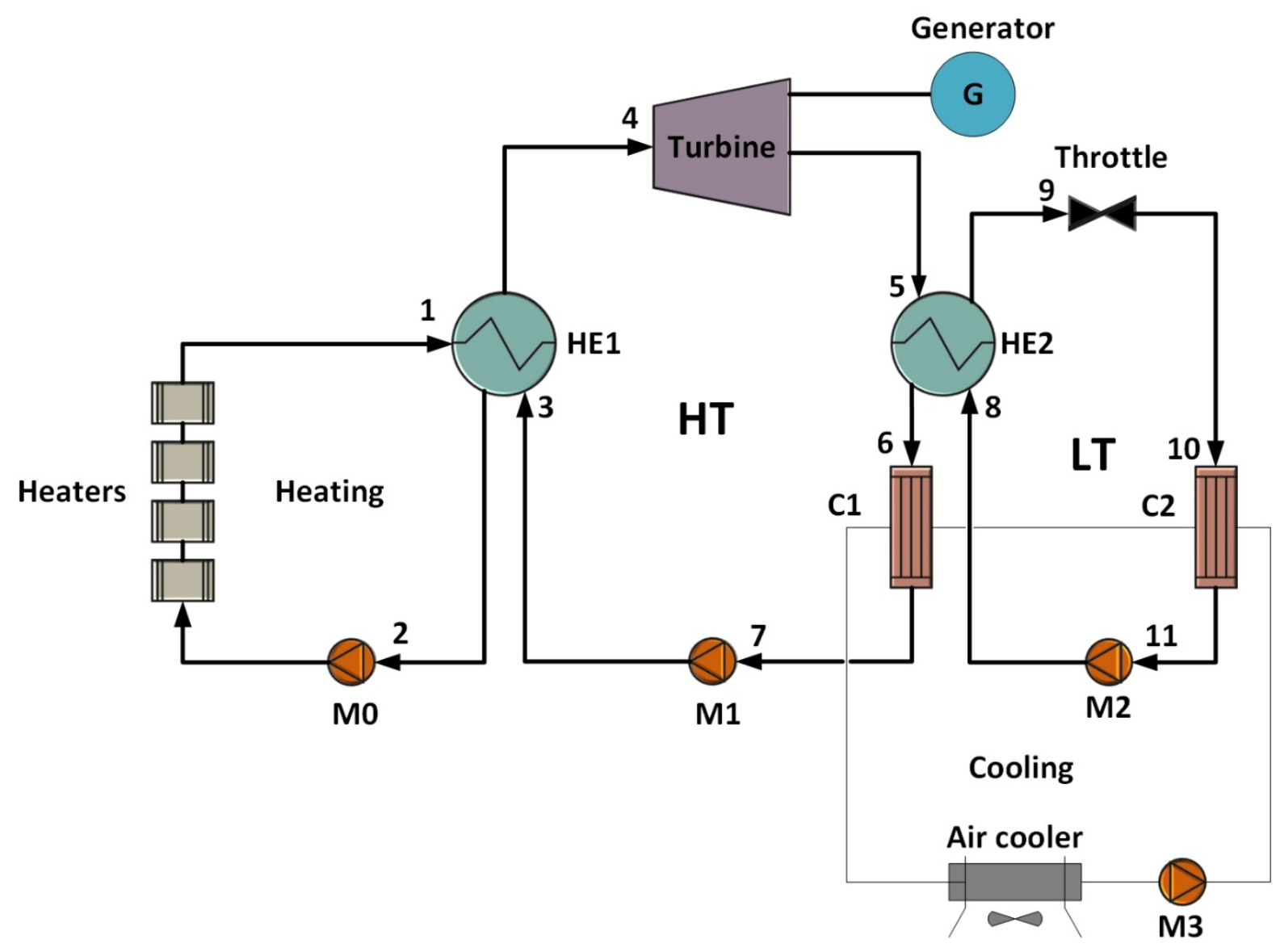

Fig. 1. Layout of the cascaded two-ORC system investigated experimentally in the present work. 


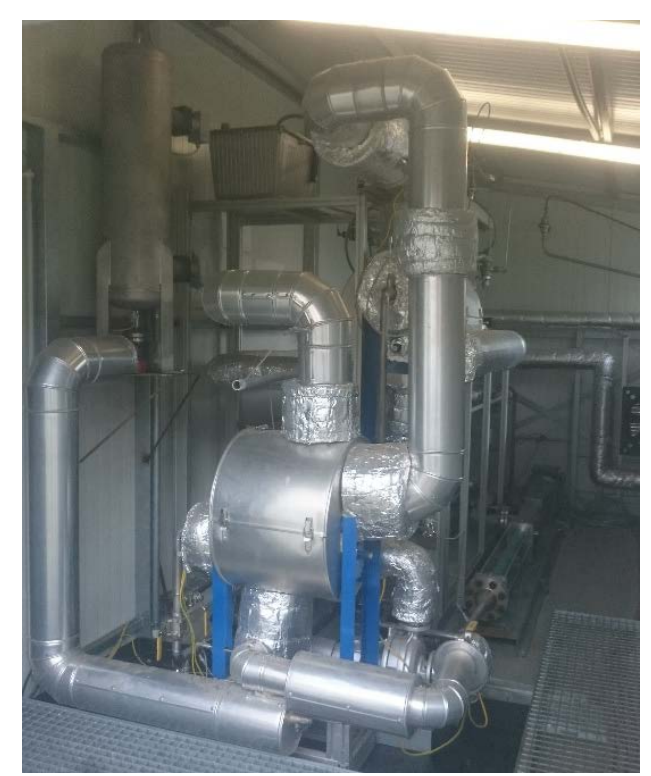

(a)

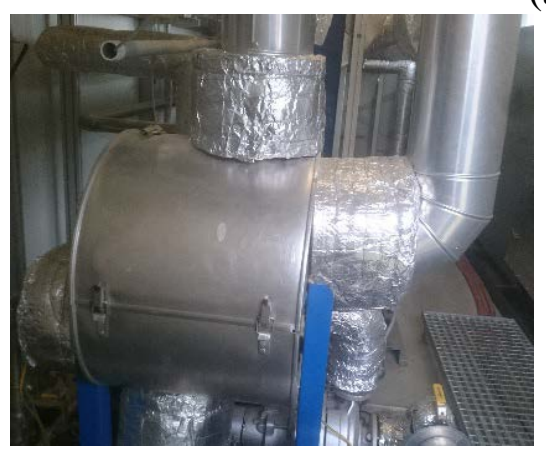

(b)

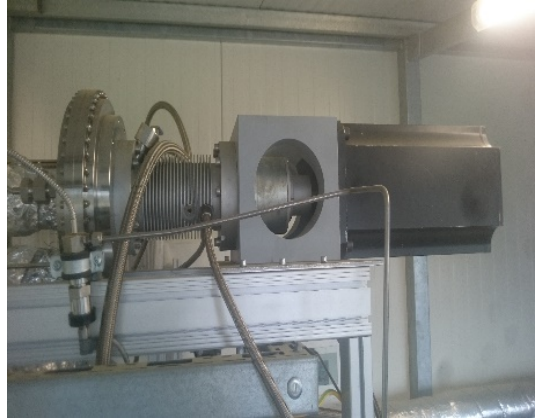

(d)



(f)

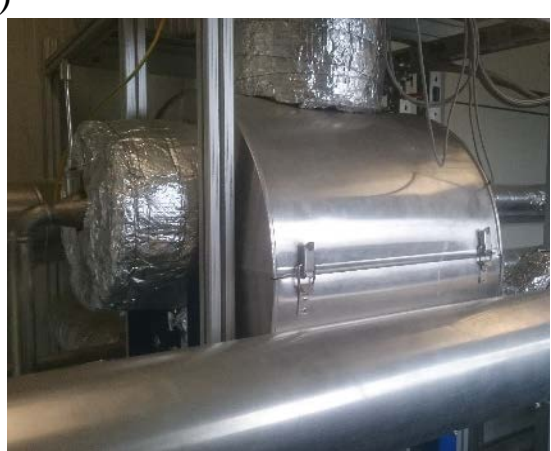

(c)

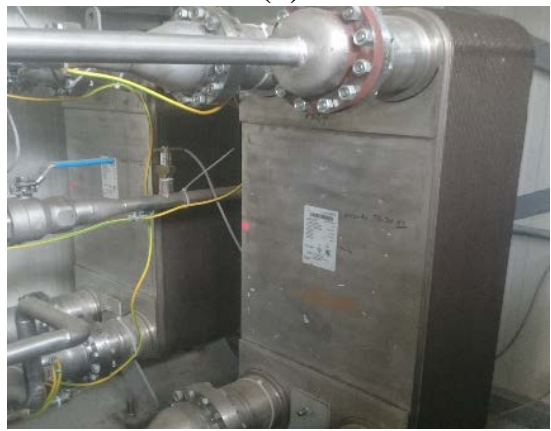

(e)

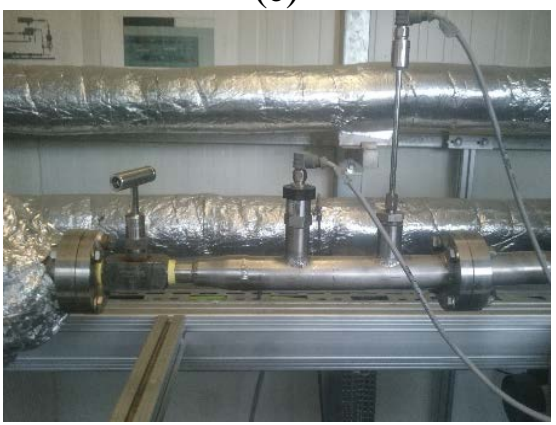

(g)

Fig. 2. (a) The cascaded two-ORC test rig was in a container due to safety considerations, (b) HT cycle heat exchanger, (c) LT cycle heat exchanger, (d) HT cycle turbine and generator, (e) condensers of HT and LT cycles, (f) pumps of HT and LT cycles, (g) LT cycle throttle. 


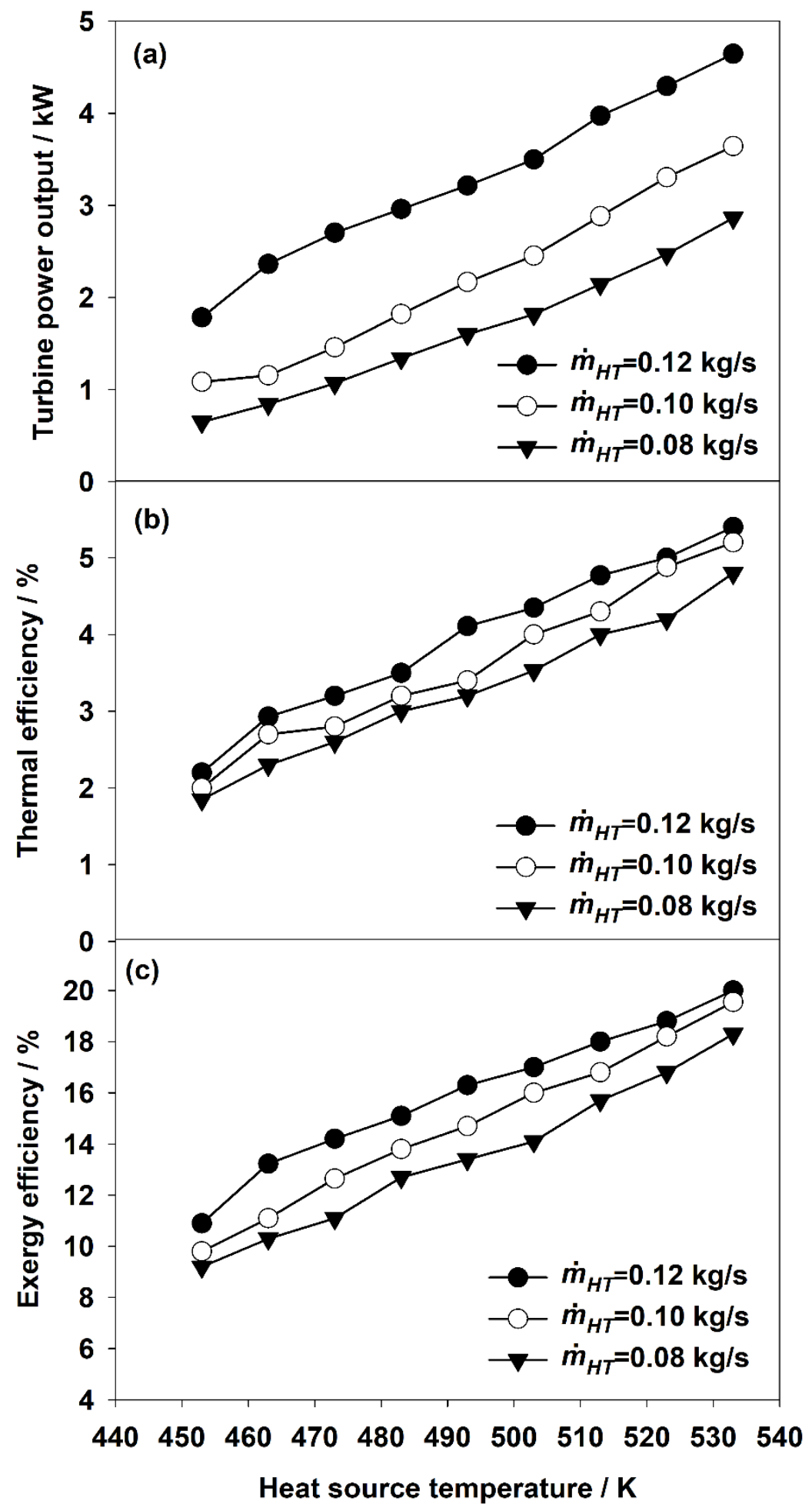

Fig. 3. Variation of (a) turbine power output, (b) thermal efficiency and (c) exergy efficiency of the HT cycle as a function of heat source temperature for a varying cyclopentane mass flow rate. 


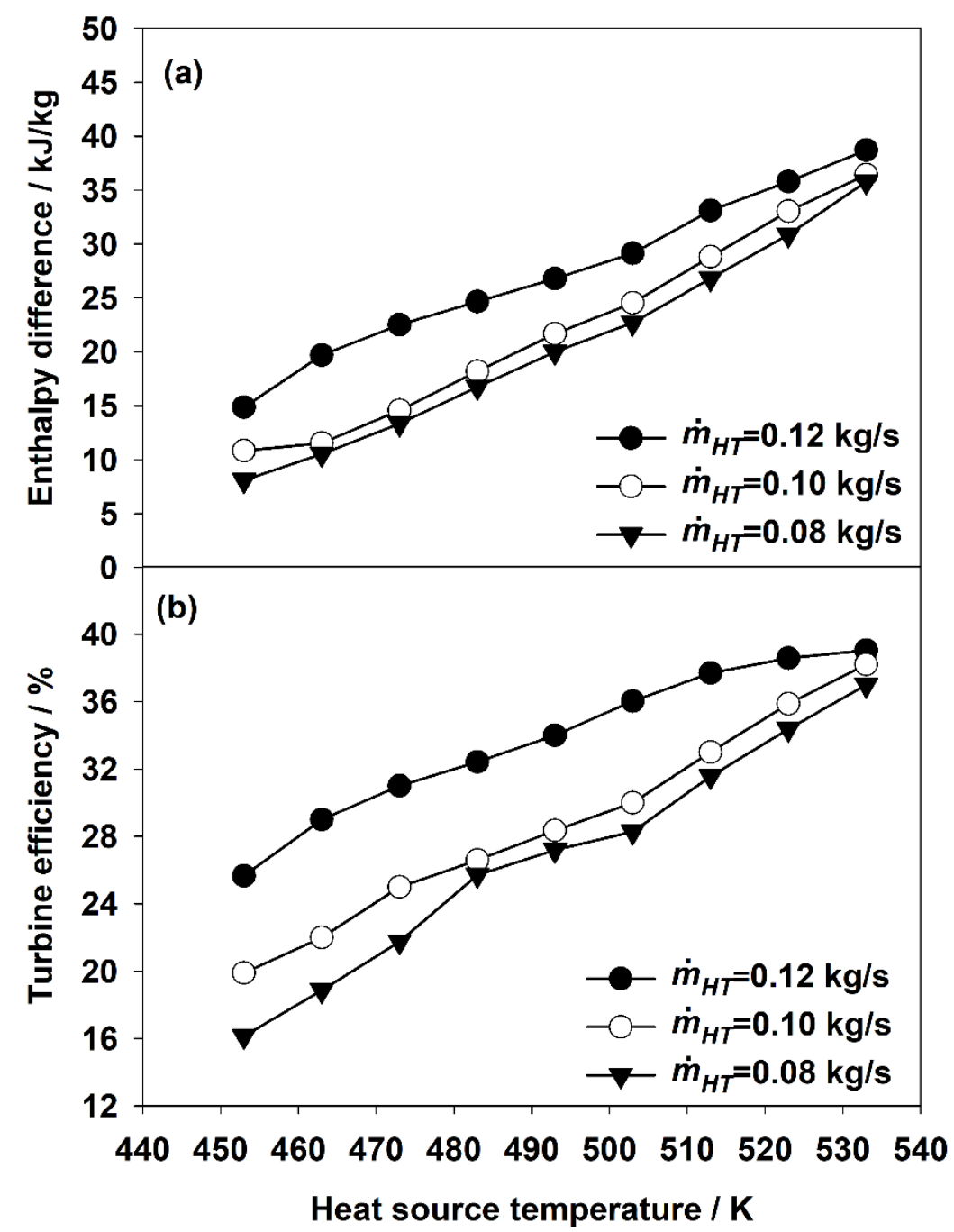

Fig. 4. Variation of (a) enthalpy difference across the turbine and (b) turbine efficiency as a function of heat source temperature for a varying cyclopentane mass flow rate. 


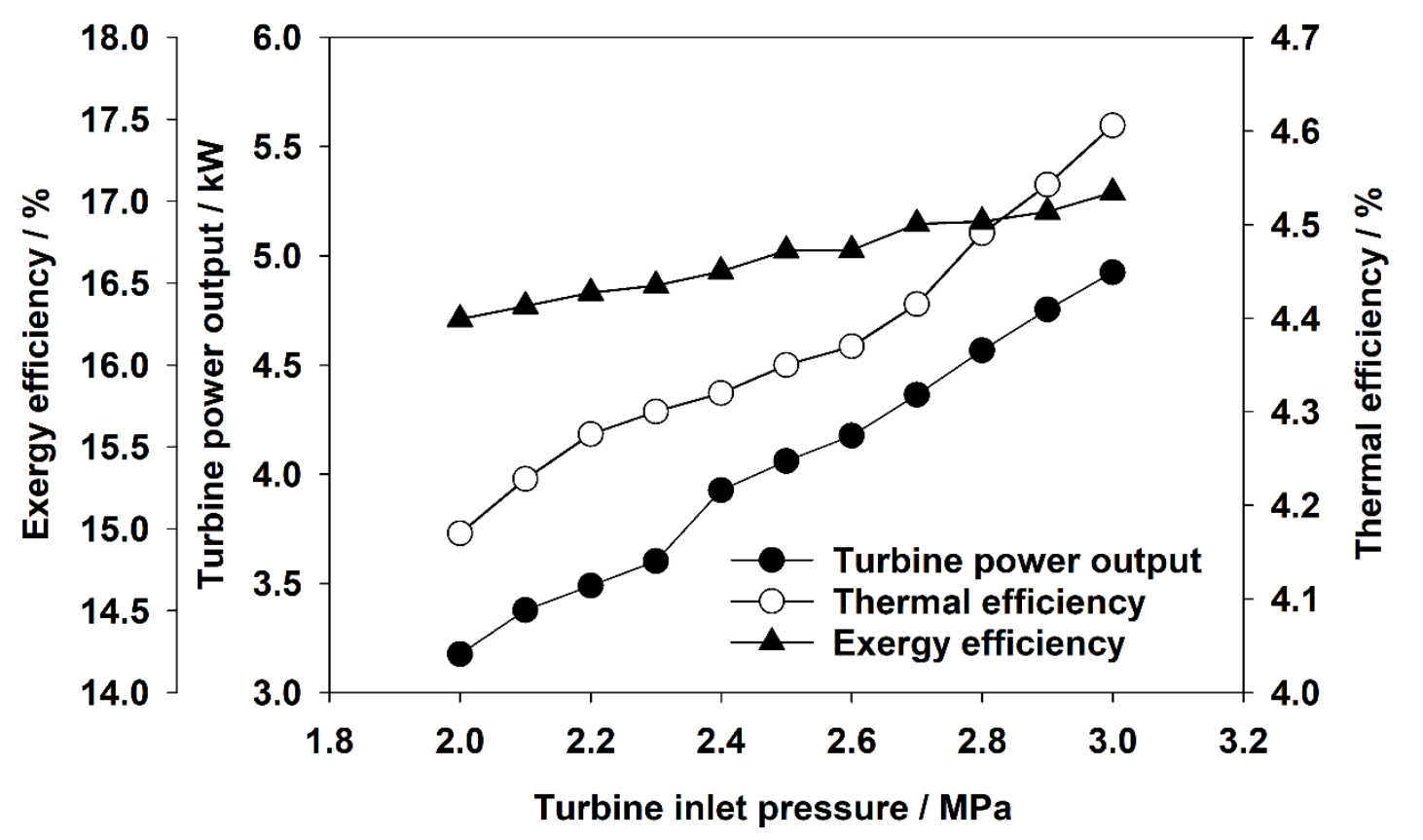

Fig. 5. Variation of turbine power output, thermal efficiency and exergy efficiency as a function of turbine inlet pressure.

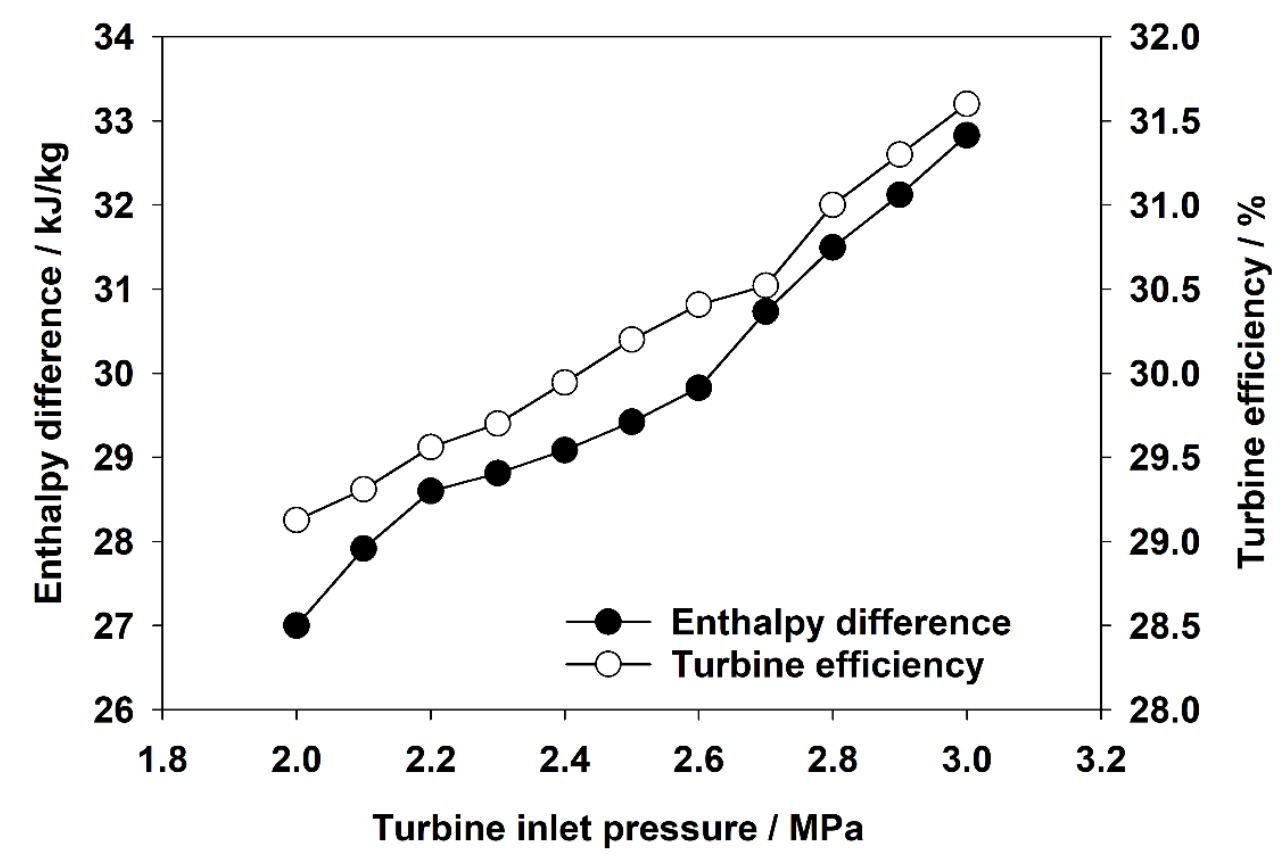

Fig. 6. Variation of enthalpy difference and turbine efficiency as a function of turbine inlet pressure. 


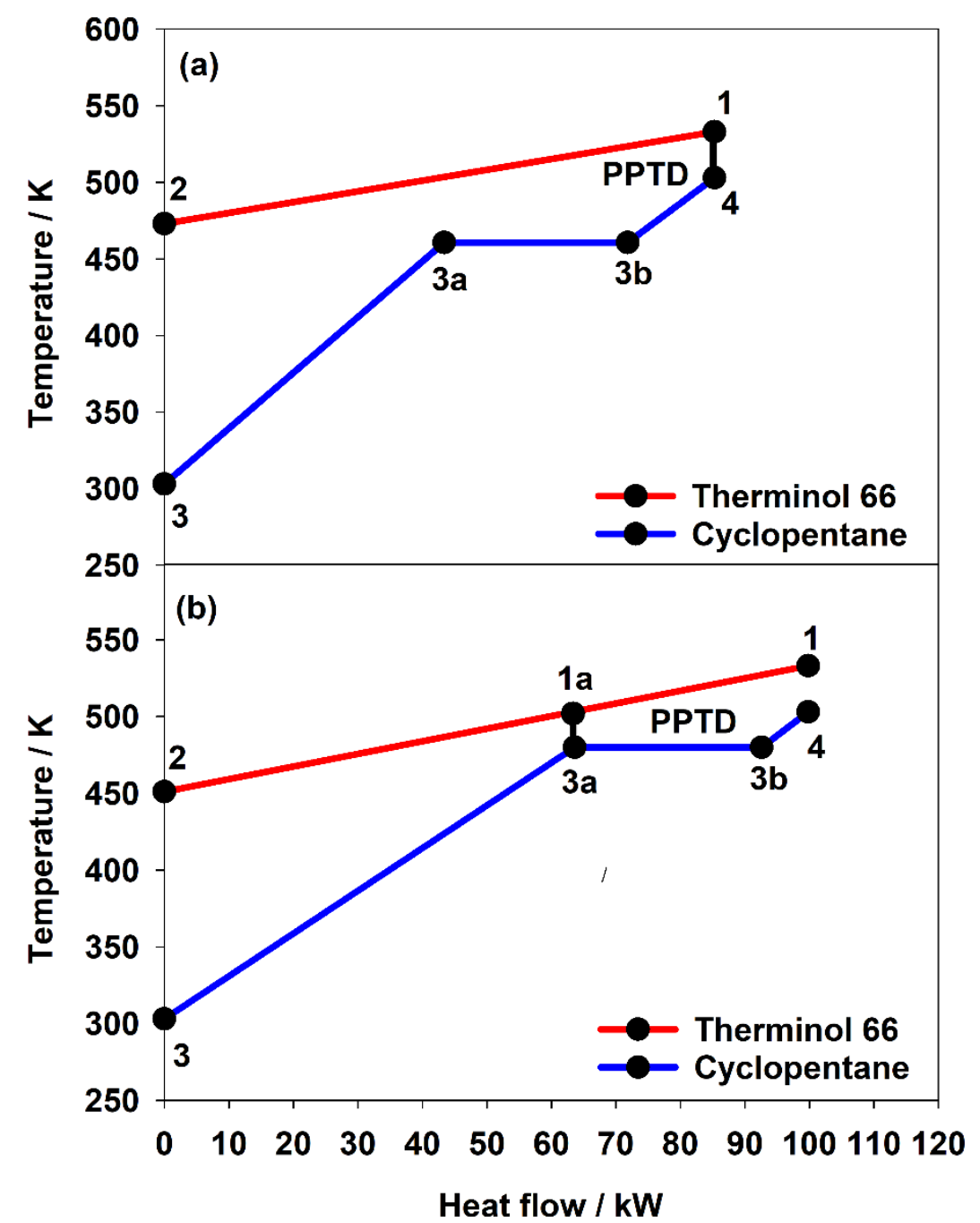

Fig. 7. Comparison of heat transfer, temperature profiles and PPDT in the heat exchanger HE1 under (a) condition 1 and (b) condition 2. 


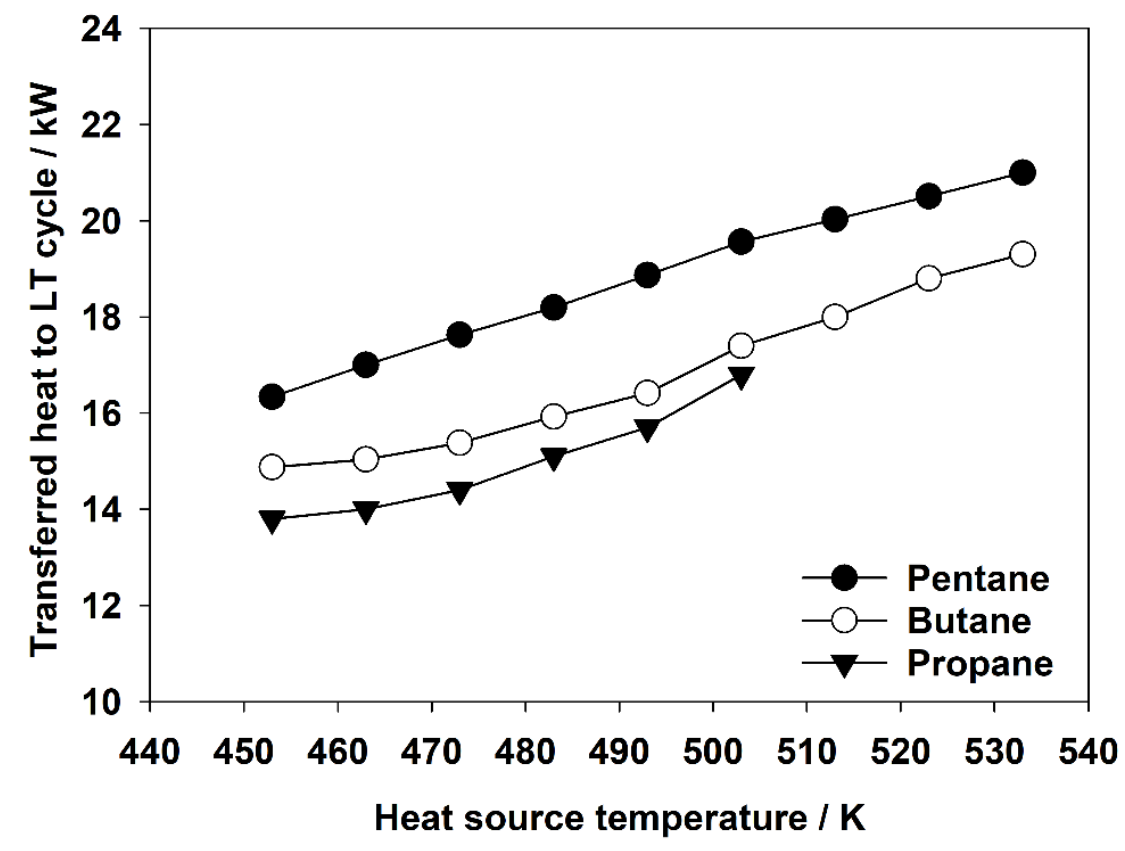

Fig. 8. Variation of heat flow from the HT cycle to the LT cycle as a function of heat source temperature for three different LT cycle working fluids. 

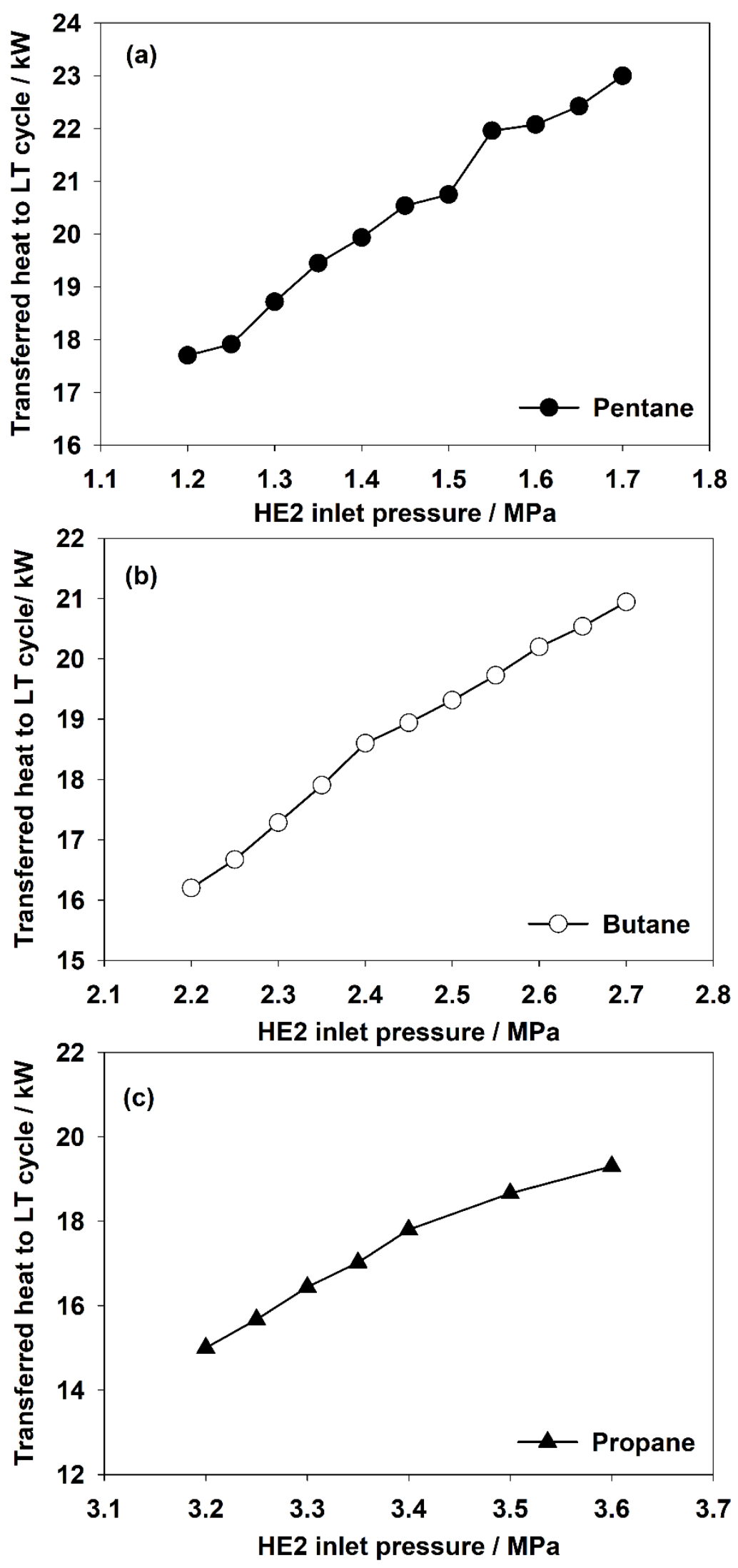

Fig. 9. Variation of heat transfer from the HT cycle to the LT cycle as a function of inlet pressure of heat exchanger HE2, by using (a) pentane, (b) butane and (c) propane as a working fluid in the LT cycle. 


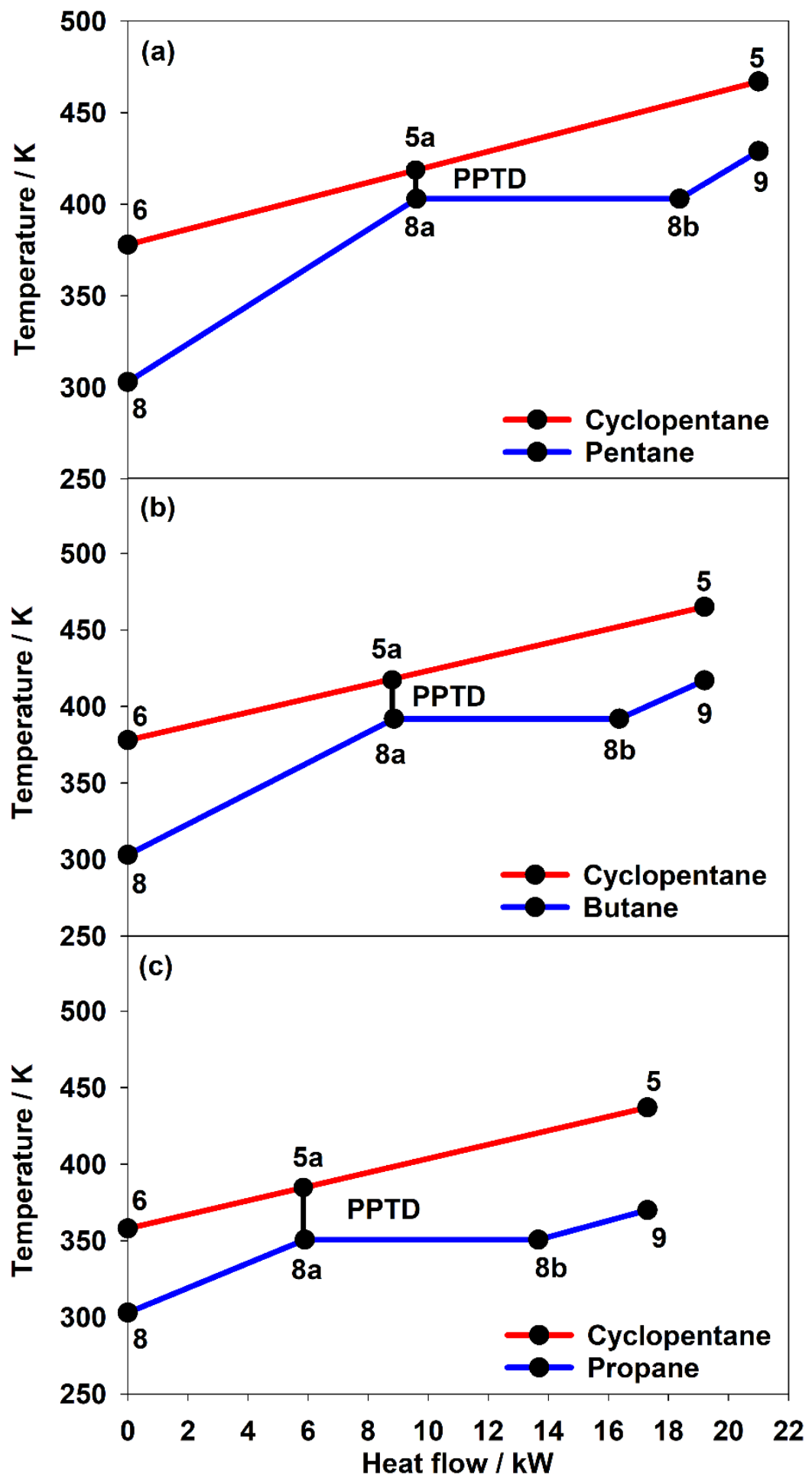

Fig. 10. Comparison of heat transfer, temperature profiles and PPTD in heat exchanger HE2 under condition 3, by using (a) pentane, (b) butane and (c) propane as a working fluid in the LT cycle. 


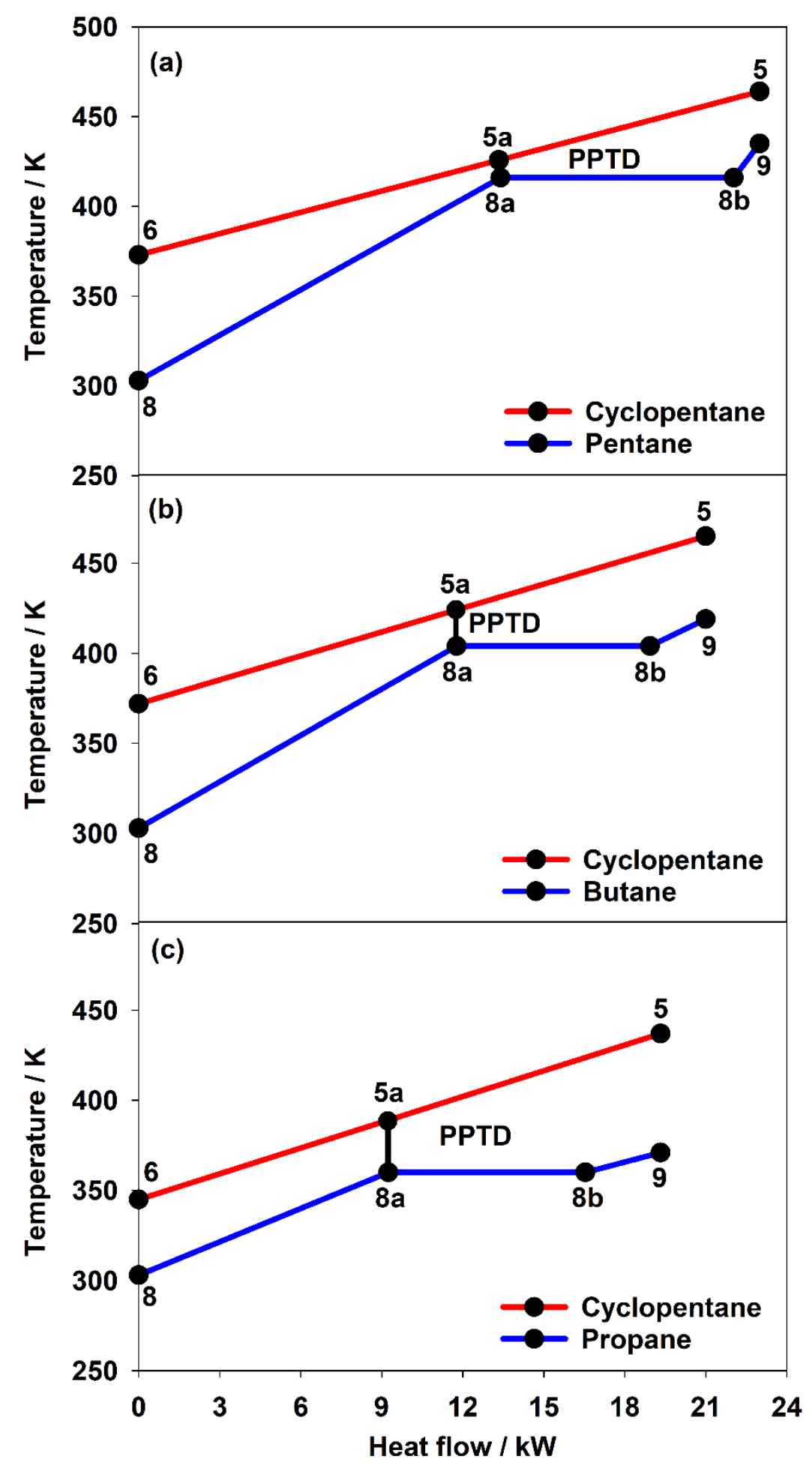

Fig. 11. Comparison of heat transfer, temperature profiles and PPTD in heat exchanger HE2 under condition 4, by using (a) pentane, (b) butane and (c) propane as a working fluid in the LT cycle. 
Table 1: Basic components of the cascaded two-ORC test rig.

\begin{tabular}{lcc}
\hline \multicolumn{1}{c}{ Component } & Type & Range \\
\hline M0 & Allweiler NTWH 25 200 & Max. 0.3 kW, 0.7 kg/s, 0.8 MPa, $350{ }^{\circ} \mathrm{C}$ \\
Flow heaters & GC heat D01-00508 & $0-158 \mathrm{~kW}$ \\
M1 & Progressive cavity-NETZSCH & $-20-200{ }^{\circ} \mathrm{C}$, \\
M2 & Progressive cavity-NETZSCH & $-20-200{ }^{\circ} \mathrm{C}$, \\
HE1 & Plate \& Shell, VAHTERUS & $-20-350^{\circ} \mathrm{C},-1-6 \mathrm{MPa}$ \\
HE2 & Plate \& Shell, VAHTERUS & $-20-250^{\circ} \mathrm{C},-1-10 \mathrm{MPa}$ \\
C1 & Heat exchanger, WP 10 L-100 & Max. $2.5 \mathrm{MPa},-195-195^{\circ} \mathrm{C}$ \\
C2 & Heat exchanger, WP 10 L-100 & Max. $2.5 \mathrm{MPa},-195-195^{\circ} \mathrm{C}$ \\
Turbine & Radial flow & Max. to $325^{\circ} \mathrm{C}$ \\
Generator & Six pole synchronous & Max. to $14 \mathrm{~kW}$ \\
& servomotor
\end{tabular}

Table 2: Measuring devices of the cascaded two-ORC test rig.

\begin{tabular}{lccc}
\hline \multicolumn{1}{c}{ Variable } & Sensor type & Range & Uncertainty \\
\hline$p(\mathrm{HC})$ & Jumo & $0-0.6 \mathrm{MPa}$ & $\pm 0.5 \%$ \\
$T_{1}, T_{2}(\mathrm{HC})$ & Pt 1000 & $-40-380^{\circ} \mathrm{C}$ & $\pm 0.1 \%$ \\
$\dot{m}_{H C}(\mathrm{HC})$ & Pressure difference & $0-2.5 \mathrm{MPa}$ & $\pm 0.1 \%$ \\
$T_{3}, T_{4}, T_{5}, T_{6}, T_{7}(\mathrm{HT})$ & Pt 1000 & $-40-380^{\circ} \mathrm{C}$ & $\pm 0.1 \%$ \\
$p_{3}, p_{4}(\mathrm{HT})$ & APT & $0-6 \mathrm{MPa}$ & $\pm 0.5 \%$ \\
$p_{5}, p_{6}, p_{7}(\mathrm{HT})$ & APT & $0-1.6 \mathrm{MPa}$ & $\pm 0.5 \%$ \\
$\dot{m}_{H T}(\mathrm{HT})$ & SITRANS P DS III & $0-10 \mathrm{MPa}$ & $\leq 0.065 \%$ \\
$T_{8}, T_{9}(\mathrm{LT})$ & Pt 1000 & $-40-380^{\circ} \mathrm{C}$ & $\pm 0.1 \%$ \\
$T_{10}, T_{11}(\mathrm{LT})$ & Pt 1000 & $-40-380^{\circ} \mathrm{C}$ & $\pm 0.1 \%$ \\
$p_{8}, p_{9}(\mathrm{LT})$ & APT & $0-6 \mathrm{MPa}$ & $\pm 0.5 \%$ \\
$p_{10}, p_{11}(\mathrm{LT})$ & APT & $0-1.6 \mathrm{MPa}$ & $\pm 0.5 \%$ \\
$\dot{m}_{L T}(\mathrm{LT})$ & SITRANS P DS III & $0-10 \mathrm{MPa}$ & $\leq 0.065 \%$ \\
& & & \\
\hline
\end{tabular}

Table 3. Properties of the selected working fluids.

\begin{tabular}{ccccccccc}
\hline Substance & $M[\mathrm{~g} / \mathrm{mol}]$ & $T_{b}[\mathrm{~K}]$ & $T_{c}[\mathrm{~K}]$ & $p_{c}[\mathrm{MPa}]$ & Type & GWP & ODP & Ref. \\
\hline Propane & 44.096 & 231.036 & 369.89 & 4.25 & Wet & 3 & 0 & {$[39]$} \\
Butane & 58.122 & 272.66 & 425.13 & 3.79 & Dry & 4 & 0 & {$[40]$} \\
Pentane & 72.149 & 309.21 & 469.70 & 3.37 & Dry & 4 & 0 & {$[41]$} \\
Cyclopentane & 70.133 & 322.375 & 511.72 & 4.57 & Dry & $<1$ & 0 & {$[42]$} \\
\hline
\end{tabular}


Table 4. Basic parameters and operational conditions of the present experiments with the cascaded two-ORC test rig.

\begin{tabular}{lc}
\hline \multicolumn{1}{c}{ Parameter } & Range \\
\hline Condition 1 & \\
\hline Temperature of heat source & $0.43-533 \mathrm{~K}$ \\
Mass flow rate (HC) & $278.15-288.15 \mathrm{~kg} \mathrm{~s}$ \\
Ambient temperature & $0.101 \mathrm{MPa}$ \\
Ambient pressure & $0.08-0.12 \mathrm{~kg} \mathrm{~s}^{-1}$ \\
Mass flow rate (HT) & \\
\hline Condition 2 & $533 \mathrm{~K}$ \\
Temperature of heat source & $2.0-3.0 \mathrm{MPa}$ \\
Turbine inlet pressure & $0.48-0.55 \mathrm{~kg} \mathrm{~s}^{-1}$ \\
Mass flow rate (HC) & $0.12-0.15 \mathrm{~kg} \mathrm{~s}^{-1}$ \\
Mass flow rate (HT) & $453-533 \mathrm{~K}^{-1}$ \\
\hline Condition 3 & $0.48-0.55 \mathrm{~kg} \mathrm{~s}^{-1}$ \\
\hline Temperature of heat source & $0.12 \mathrm{~kg} \mathrm{~s}^{-1}$ \\
Mass flow rate (HC) & $0.030-0.035 \mathrm{~kg} \mathrm{~s}^{-1}$ \\
Mass flow rate (HT) & \\
Mass flow rate (LT) & $533 \mathrm{~K}$ \\
\hline Condition 4 & $1.2-3.6 \mathrm{MPa}^{-1}$ \\
\hline Temperature of heat source & $0.48-0.55 \mathrm{~kg} \mathrm{~s}^{-1}$ \\
HE2 inlet pressure & $0.12 \mathrm{~kg} \mathrm{~s}^{-1}$ \\
Mass flow rate (HC) & $0.035-0.048 \mathrm{~kg} \mathrm{~s}^{-1}$ \\
Mass flow rate (HT) & \\
Mass flow rate (LT) & \\
\hline
\end{tabular}

